\title{
The improvement of mechanical and thermal properties of polyamide 12 3D printed parts by fused deposition modelling
}

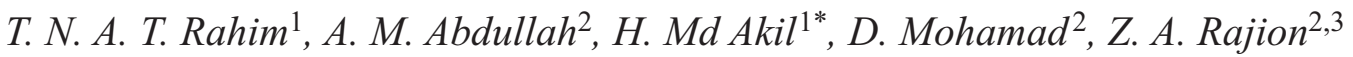 \\ ${ }^{1}$ School of Materials and Mineral Resources Engineering, Engineering Campus, Universiti Sains Malaysia, 14300 Nibong \\ Tebal, Pulau Pinang, Malaysia \\ ${ }^{2}$ School of Dental Sciences, Health Campus, Universiti Sains Malaysia, 16150 Kubang Kerian, Kelantan, Malaysia \\ ${ }^{3}$ College of Dentistry, King Saud bin Abdulaziz University for Health Sciences, Riyadh, Kingdom of Saudi Arabia
}

Received 18 April 2017; accepted in revised form 4 July 2017

\begin{abstract}
This paper addresses the utilisation of fused deposition modelling (FDM) technology using polyamide 12, incorporated with bioceramic fillers (i.e. zirconia and hydroxyapatite) as a candidate for biomedical applications. The entire production process of printed PA12 is described, starting with compounding, filament wire fabrication and finally, FDM printing. The potential to process PA12 using this technique and mechanical, thermal and morphological properties were also examined. Commonly, a reduction of mechanical properties of printed parts would occur in comparison with injection moulded parts despite using the same material. Therefore, the mechanical properties of the samples prepared by injection moulding were also measured and applied as a benchmark to examine the effect of different processing methods. The results indicated that the addition of fillers improved or maintained the strength and stiffness of neat PA12, at the expense of reduced toughness and flexibility. Melting behaviours of PA12 were virtually insensitive to the processing techniques and were dependent on additional fillers and the cooling rate. Incorporation of fillers slightly lowered the melting temperature, however improved the thermal stability. In summary, PA12 composites were found to perform well with FDM technique and enabling the production of medical implants with acceptable mechanical performances for non-load bearing applications.
\end{abstract}

Keywords: processing technologies, fused deposition modeling, 3D printing, polymer composites, mechanical properties

\section{Introduction}

Fused deposition modelling (FDM) is one of the most widely used 3D printing techniques employed over the last few years in engineering and medical fields. FDM can develop intricate parts and components, without the need for human intervention. This technology has enabled product customisation for smallscale production, with polymers still being the most widely used materials in the FDM process, especially acrylonitrile butadiene styrene (ABS) $[1,2]$, polylactic acid (PLA) [3] and poly( $\varepsilon$-caprolactone) (PCL) $[4,5]$. FDM technology has the potential to manufacture complex parts quickly and with the added advantage of being more cost-effective as compared to other conventional methods. However, the application of FDM to produce parts and components is limited due to exhibiting lower mechanical properties, compared to other conventional means to produce moulded parts. This originates from inherent limitations of the layering technique, resulting in poorly bonded adhesion between layers, and the formation of small portions of porosities [4] in addition to the heterogeneous microstructure of FDM parts.

Despite all these weaknesses, FDM has so far been the most preferred method for productions that have very low volume needs due to the absence of considerable initial costs that come with specially tooled dies acquired by moulding techniques. Since changing

${ }^{*}$ Corresponding author, e-mail: hazizan@usm.my

(C) BME-PT 
the layering technique into conventional technique may be both impractical and expensive, considerable research has focused on improving material performance and functionality by developing polymer composites for FDM feedstocks [6]. Early studies concentrated on using ABS and PLA filled with micron or nanoscale particles, such as graphene, short fibre, montmorillonite, metals and TCP [7-12] to improve mechanical properties. The results of these studies highlighted that all mechanical properties of printed composites demonstrated some improvement either in the modulus or both the strength and modulus as compared to pure polymer.

The technology associated with FDM also provides significant opportunities within the medical and surgical areas, particularly for fabricating bone implants and for tissue engineering [13]. However, an issue remains when applying conventional FDM materials for medical applications, given the biocompatibility of polymer. Some researchers have expressed their concern regarding the toxicity of ABS and have attempted to develop a biocompatible FDM feedstock produced from polylactic acid (PLA) [11, 14] and polycaprolactone (PCL) $[15,16]$. Although these materials have provided scaffolds with different internal architectures and controlled porosity, the lack of durability and insufficient mechanical properties has limited their use. The result is a product that can only be used as a temporary fix, which has led researchers to develop new materials for bone replacement, using procedures for permanent fix (bone) reconstruction.

Among the most promising biocompatible polymers with acceptable mechanical properties [17], and excellent processability with the FDM technique [18], is polyamide or nylon. Polyamide used as an engineering polymer exhibits the toughest material characteristics compared to other polymers used in the industry. It has superior bonding adhesion between layers ( $z$-axis lamination) of any comparable FDM thermoplastic $[18,19]$. The polyamide can be divided into two groups, aliphatic or aromatic polyamide. However, the former polyamide is the most important class of engineering thermoplastic and is extensively used for medical implants or in tissue engineering [20-24]. Furthermore, they are amorphous or only moderately crystalline, making it suitable to be utilised for the FDM process.

Although the polymer composites have been developed for the FDM technique, additional scientific research on developing new FDM materials is essential to meet the requirements of more substantial applications, particularly for medical and surgical implants. All existing polyamide superiorities are encouraging the development of a new polyamide, incorporated with bioceramic fillers and to evaluate structural properties such as strength, modulus and toughness of FDM printed parts. In the present study, PA12 was selected due to exhibiting lower processing temperatures and is often preferred for producing prototypes and parts as compared with other polyamides. In the interim, bioceramic materials i.e. zirconia and hydroxyapatite have been incorporated as reinforcing fillers. A frequent processing route that is followed in the polymer industry and is often specifically used in medical or dental applications is to fabricate the multiphase composites by using various types of fillers or dispersing agents [25-28]. By incorporating the supplementary reinforcement into the matrix resin, a synergistic effect may be achieved in terms of improvements in mechanical, thermal and biological properties. Hydroxyapatite (HA) has a composition and structure very close to natural bone apatite and shows excellent osteoconductivity and osteoinductivity [20,29]. Meanwhile, zirconia has unique biomechanical properties that include mechanical strength and fracture toughness. Zirconia also possesses good radio-opacity, which makes it clearly visible on a radiograph, thus allowing researchers to monitor its function [18]. The mechanical properties of the injection moulded (IM) parts are evaluated and used as a benchmark to study the dependence of the production technique. The knowledge of these properties is critical for predicting the performance of an end-use product and how the part will function in demanding circumstances and applications. Thermal properties of polyamide 12 composites are measured and useful in estimating the processing conditions and studying the effect of fillers. It was found that PA12 composites worked well with the FDM technique and extremely helpful for biomedical applications.

\section{Materials and methods}

\subsection{Raw materials}

Polyamide 12 powder (PA2200), supplied by EOS $\mathrm{GmbH}$, Singapore was used in this study. Due to hygroscopic properties, all polyamide samples were initially dried in a vacuum oven at $90^{\circ} \mathrm{C}$ for at least 24 hours, before any fabrication or tests performed. Sigma-Aldrich, Malaysia supplied two bioceramic fillers, (i.e. zirconia (230693) and hydroxyapatite 
Table 1. Compositional of PA12 and PA12 composites

\begin{tabular}{|l|c|c|c|c|}
\hline \multirow{2}{*}{ Sample } & \multicolumn{3}{|c|}{ Raw material } & Filler content \\
\cline { 2 - 4 } & PA12 & HA & $\mathbf{Z r O}_{2}$ & \\
\hline Unfilled PA12 & 100 & 0 & 0 & 0 \\
\hline $10 \%$ filled PA12 & 90 & 10 & 0 & 10 \\
\hline $15 \%$ filled PA12 & 85 & 10 & 5 & 15 \\
\hline $20 \%$ filled PA12 & 80 & 10 & 10 & 20 \\
\hline $30 \%$ filled PA12 & 70 & 10 & 20 & 30 \\
\hline $40 \%$ filled PA12 & 60 & 10 & 30 & 40 \\
\hline
\end{tabular}

(21223)). The purity of zirconia $\left(\mathrm{ZrO}_{2}\right)$ was $99 \%$, whereas the purity of hydroxyapatite (HA) was $\geq 90 \%$. The composition is shown in Table 1.

\subsection{Sample preparation}

Polyamide 12 and fillers were premixed and subsequently compounded via a twin-screw extruder (PSM 30, Sino-Alloy Machinery) by a screw diameter of $31.2 \mathrm{~mm}$ and $L / D$ ratio of 40 . The screw speed was set at $50 \mathrm{rpm}$ and the processing temperatures were ranged from $180-200^{\circ} \mathrm{C}$, starting from hopper to the extrusion die. The obtained pellets were then fed into the Kompaktextruder KE19 single screw extruder (Brabender) (screw diameter $=19 \mathrm{~mm} ; L / D$ ratio $=25$ ) and drawn into a filament form. A circular fabricated die with a $2 \mathrm{~mm}$ diameter was used at the processing temperatures of $180-200^{\circ} \mathrm{C}$ and a screw speed of $40 \mathrm{rpm}$. The filament was then spooled to the winder as it was being extruded. In this study, the winder (Filastruder, USA) was self-assembled from a DIY kit, with several modifications made to the motor and its power supply. This enabled the speed of the extruder and winder to be matched until the diameter of the filament fell to $1.65-1.85 \mathrm{~mm}$. The filament was used as a feedstock for the 3D printer (MakerBot Replicator 2X) using several steps before printing the material. The process commenced with constructing the virtual 3D models using SolidWorks 3D Computer Aided Design (CAD) software. In this study, the model representing tensile, flexural and impact samples were designed in accordance with ASTM standard. The design file was exported into an STL file format and reviewed by the Makerware software program (i.e. printer software). The parameters to be used for printing (e.g. print temperature, extruder temperature, layer height, etc.) were configured as shown in Table 2. The digital model (STL file) was then converted into a list of commands which the 3D printer could interpret and execute, called $G$-code or slicing. After the $G$-code had been created, it was sent to the printer via a USB connection and the 3D model was finally printed with the feedstock polyamide onto a platform until the process was completed. Figure 1 illustrates the overall 3D printing process. Basically, build orientation plays an important role in improving mechanical properties. There are three different types of orientations: horizontal, vertical and perpendicular [4]. In the present study, all samples were printed in the horizontal build direction only since most studies [7, 30-32] have reported on the superiority of mechanical properties for both horizontal and vertical directions compared to the perpendicular direction. During the printing process, an extruded filament would be printed at a certain layer extrusion path, otherwise known as raster orientation. The specimens were automatically

Table 2. Summary of process parameters in Makerware for processing PA12 and PA12 composites

\begin{tabular}{|l|c|}
\hline Resolution & standard \\
\hline Percentage of material infill & $100 \%$ \\
\hline Number of shells & 2 \\
\hline Layer of height & $0.3 \mathrm{~mm}$ \\
\hline Pattern orientation & $0^{\circ}, 90^{\circ},-45^{\circ}, 45^{\circ}$ \\
\hline Speed while printing & $20 \mathrm{~mm} / \mathrm{s}$ \\
\hline Speed while traveling & $30 \mathrm{~mm} / \mathrm{s}$ \\
\hline Nozzle temperature & $200^{\circ} \mathrm{C}$ \\
\hline Platform temperature & $110^{\circ} \mathrm{C}$ \\
\hline
\end{tabular}

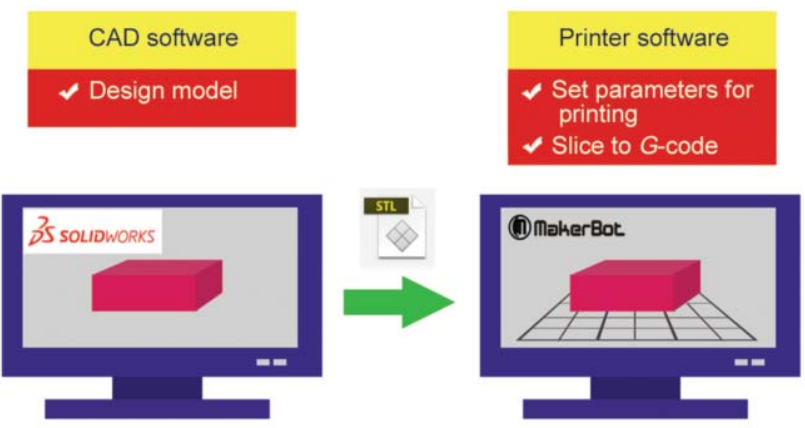

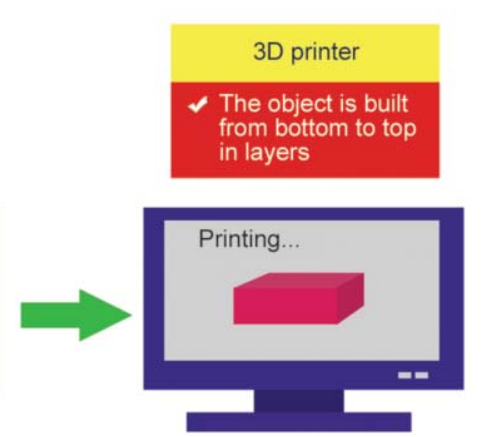

Figure 1. Schematic diagram of 3D printing process starts from designing, setting the parameters, slicing to $G$-code and printing 


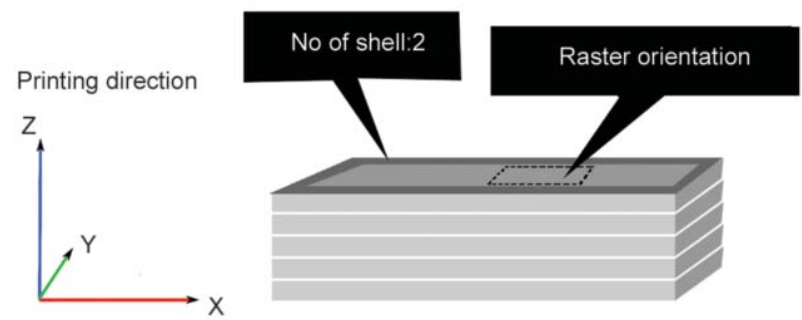

Figure 2. Types of raster orientation during printing process

printed at different raster orientation angles of 0,90 , -45 and $45^{\circ}$, as shown in Figure 2.

Furthermore, the specimens for mechanical testing (tensile, flexural and impact) were prepared using a conventional polymer technique, i.e. injection moulding (BOY 22M, BOY Machines) to make comparisons with the FDM technique. The temperature for each zone ranged from 180 to $250^{\circ} \mathrm{C}$, with the injection pressure set at 90 bar.

\subsection{Characterisation of polyamide composites 2.3.1. Mechanical properties}

In the present study, tensile and flexural properties were measured using a universal testing machine (Model 3366, Instron with a $10 \mathrm{kN}$ load cell), at a temperature of $23 \pm 2{ }^{\circ} \mathrm{C}$. The main difference among these properties is based on the direction of the forces. Most of the previous literatures $[1,2,10,33,34]$ normally presented tensile data as a fundamental material property in the design of thermoplastic polymer composites. However, the tensile strength data alone might be insufficient in real applications, since the load is usually derived from a combination of compressive and tensile strengths. Thus, it is also important to study materials under bending condition. The specimens were prepared by FDM 3D printing and injection moulding according to ASTM Standard D638 and ASTM D790, respectively. The gauge length and support length were set at 70 and $50 \mathrm{~mm}$, respectively. The test speed for both tests was set at $10 \mathrm{~mm} / \mathrm{min}$. A notched Izod impact test was also conducted at ambient room temperature using an impact pendulum tester (Model 5101, Zwick) according to ASTM Standard D256. For all the tests carried out, six measurements were performed for each material.

\subsubsection{Fourier transform infrared spectroscopy (FTIR)}

The FTIR spectra of the representative samples and hydroxyapatite filler were captured using an infrared spectrometre machine (Spectrum One, Perkin-Elmer)
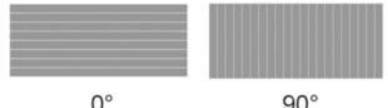

$90^{\circ}$
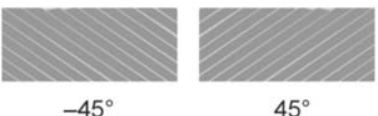

$45^{\circ}$

over a wave number range of $500-4000 \mathrm{~cm}^{-1}$, scanned 32 times.

\subsubsection{Morphological analysis}

In determining the morphology of both zirconia and hydroxyapatite fillers, the as-received fillers were imaged using a field emission scanning electron microscope (FESEM) (Supra $35 \mathrm{VP}$, Carl Zeiss) at $10 \mathrm{kV}$. The fracture surfaces of the test bars following the impact testing were used to observe the pattern of morphology due to the different processing techniques utilised and to observe filler distribution in the polyamide matrix. The zirconia and hydroxyapatite fillers were identified using an energy dispersive X-ray (EDX) elemental analysis tool.

\subsubsection{Thermal properties}

Thermal analysis of polyamide samples was conducted using differential scanning calorimetry (Pyris 6, Perkin-Elmer) to investigate the difference of thermal behaviours between the pelletised and printed samples. For printed samples, the samples were randomly collected at the middle part, made up of several layers $(\approx 4$ layers). Furthermore, it is assumed that all samples would experience the same thermal stresses during the printing process. The scanning was performed using temperature ranges of 30 to $230^{\circ} \mathrm{C}$ at a heating/cooling rate of $10^{\circ} \mathrm{C} /$ min under an inert nitrogen atmosphere. In all cases, the samples were kept at $230^{\circ} \mathrm{C}$ for 5 minutes before cooling to eliminate any previous thermal history. The samples were then cooled to $30^{\circ} \mathrm{C}$ at $10^{\circ} \mathrm{C} / \mathrm{min}$ and reheated to $230^{\circ} \mathrm{C}$ at $10^{\circ} \mathrm{C} / \mathrm{min}$. By using the heat of fusion for a $100 \%$ crystalline PA12 as $209.2 \mathrm{~J} / \mathrm{g}$ [35], the degree of crystallinity of PA12 was determined from the enthalpies obtained by DSC using the Equation (1):

$X_{\mathrm{c}}=\frac{\Delta H_{\mathrm{m}}}{(1-\Phi) \Delta H_{\mathrm{m}}^{\circ}} \cdot 100$

where $\Delta H_{\mathrm{m}}$ is the apparent fusion enthalpy of the matrix PA12 in the composite, $\Delta H_{\mathrm{m}}^{\circ}$ is the theoretical 
enthalpy of melting for $100 \%$ crystalline PA12 polymer, and $\Phi$ is the weight fraction of the filler in the composite.

The same samples were categorised to determine their thermal stability using a thermogravimetric analyser (Pyris 6, Perkin-Elmer). The specimens were then scanned starting from an ambient room temperature up to $600{ }^{\circ} \mathrm{C}$ at a heating rate of $10^{\circ} \mathrm{C} /$ min under a nitrogen gas flow.

\subsubsection{X-ray analysis (XRD)}

A wide-angle X-ray diffraction (XRD) spectra of PA12 composites was carried out in reflection mode on a diffractometer (MRD PW3040, Panalytical $\mathrm{X}$ 'Pert PRO), using Ni-filtered $\mathrm{Cu} \mathrm{K} \alpha$ radiation source $\lambda=1.5406 \AA$ at a scanning rate of $3 \% \mathrm{~min}$, a voltage $=40 \mathrm{kV}$ and current $=30 \mathrm{~mA}$ over the range $2 \theta$ : $10-80^{\circ}$. Scans were performed on sliced injection moulded and printed samples. For injection moulded samples, the surfaces of each sample were polished before the analysis to obtain an acceptable level of transmitted intensity.

\section{Results and discussion}

\subsection{Mechanical properties}

The primary objective of this study was to evaluate the capability of a fused deposition modelling (FDM) technique for producing polyamide 12 (PA12) composites, by incorporating zirconia and hydroxyapatite as fillers and note the effect of the FDM processing technique on the properties of the PA12 composites. In order to obtain an optimised composition, the effect of filler content was examined for different filler/resin combinations. Because the mechanical properties of part built by FDM technique is not possible to mimic with the conventional part, the study also aims to find the percentage loss of FDM part by using injection moulded (IM) properties as the benchmark and lastly to correlate the printed properties with the requirements of biomedical implant application. Apart from having good biocompatibility and processability, the implant should possess an acceptable strength to sustain the cyclic loading endured by the joint movement. During daily activities, the bones are subjected to a stress of approximately $4 \mathrm{MPa}$, while the tendon and ligament would experience a maximum stress ranging from 40-80 MPa [36]. On the other hand, there are also implants that are used for low or non-load bearing applications. These implants have lower strength and modulus but good ductility compared to high load bearing implants. All the types have their own relative merits and demerits that are particularly suitable for specific applications. Most of the commercialised and FDA-approved polymer-based implants have strengths ranging from 20 to $140 \mathrm{MPa}[36,37]$.
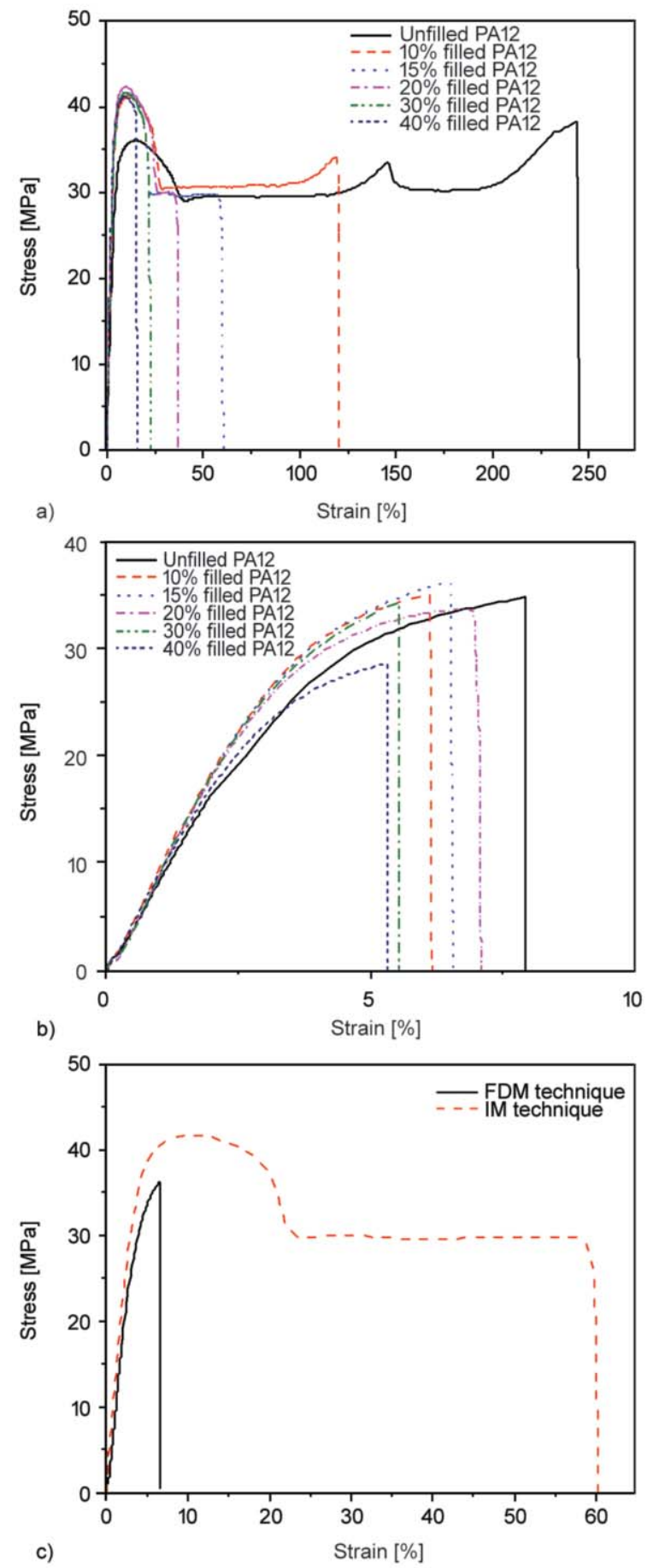

Figure 3. Typical stress-strain diagrams generated from tensile test data of representative pure PA12 and PA12 composites for (a) injection moulded samples, (b) printed samples and (c) printed and injection moulded samples 


\subsubsection{Tensile strength}

Typical tensile stress-strain diagrams representative of the specimens are illustrated in Figure 3, and data values graphically represented in the line chart, are shown in Figure 4. A different pattern was observed in the samples indicating that the mode of failure was altered due to differences in the filler content and processing techniques. The pure and low filler percentage of IM PA12 demonstrated high ductility, possessing a high resistance to deformation occurring (refer Figure 3a). The pure IM PA12 could be stretched beyond its full gauge length of the specimen, resulting in higher stress at break than the yield stress. However, as the concentration of fillers increases, the mode of fracture changes from ductile to brittle. The highly-filled IM PA12 composites (30-40 wt $\%$ filler loading) did not elongate a lot before breaking. Similar behaviour was also observed for all FDM PA12 samples (refer Figure 3b). The difference in the processing technique contributes to a ductile-to-brittle transition in PA12, which can be compared between the stress-strain curves of FDM and IM technique (refer Figure 3c).

The formation of multiple layers revealed under FESEM examination (Figure 5a-5b) illustrates a printed part consisting with an entirely different microstructure than the IM part (Figure 5c-5d). During the printing process, each thread line adheres to one another to build a layer and quickly solidifying after being deposited. The subsequent layer which is still hot, would be fused together with the previous layer and this process continues until all layers of the part are complete. The consolidation of the hot layer into a frozen layer may result a poor interfacial bonding between layers, thereby weakening the structural integrity of the FDM part. In addition, the formation of small gaps as illustrated in the FDM samples (refer Figure 5b) can also act as one of the stress concentrating factors which may lower the strength of the FDM part. In contrast to injection moulding technique, the presence of high pressure during IM process would produce a same material with relatively consistent

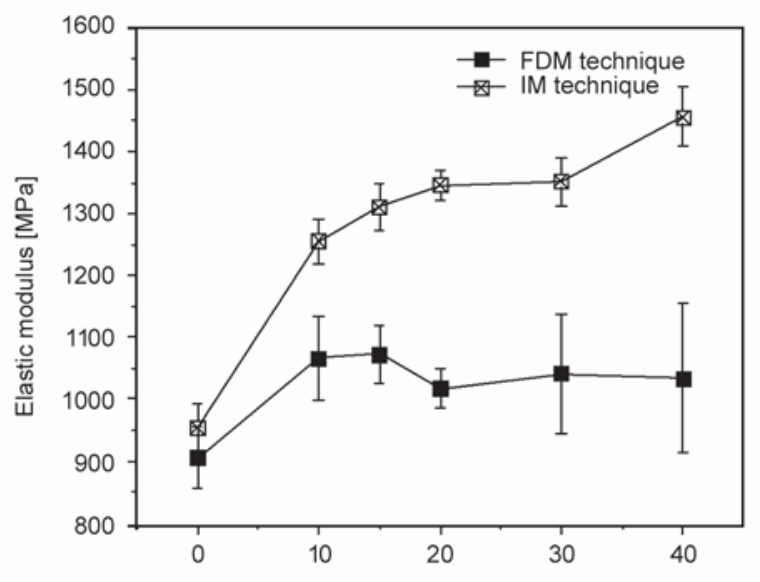

b)

Filler content [wt \%]

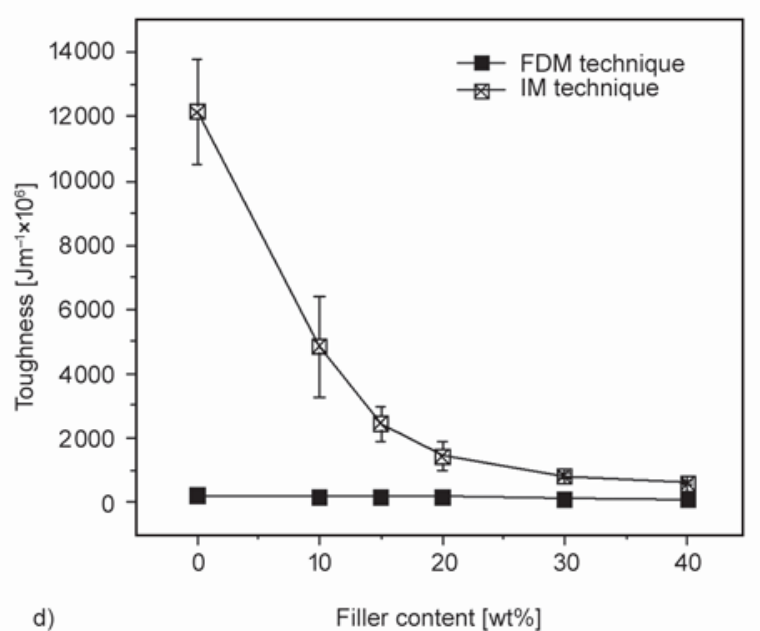

Figure 4. Tensile properties of printed and injection moulded of pure PA12 and PA12 composites: (a) tensile strength at yield, (b) elastic modulus, (c) maximum strain and (d) toughness 

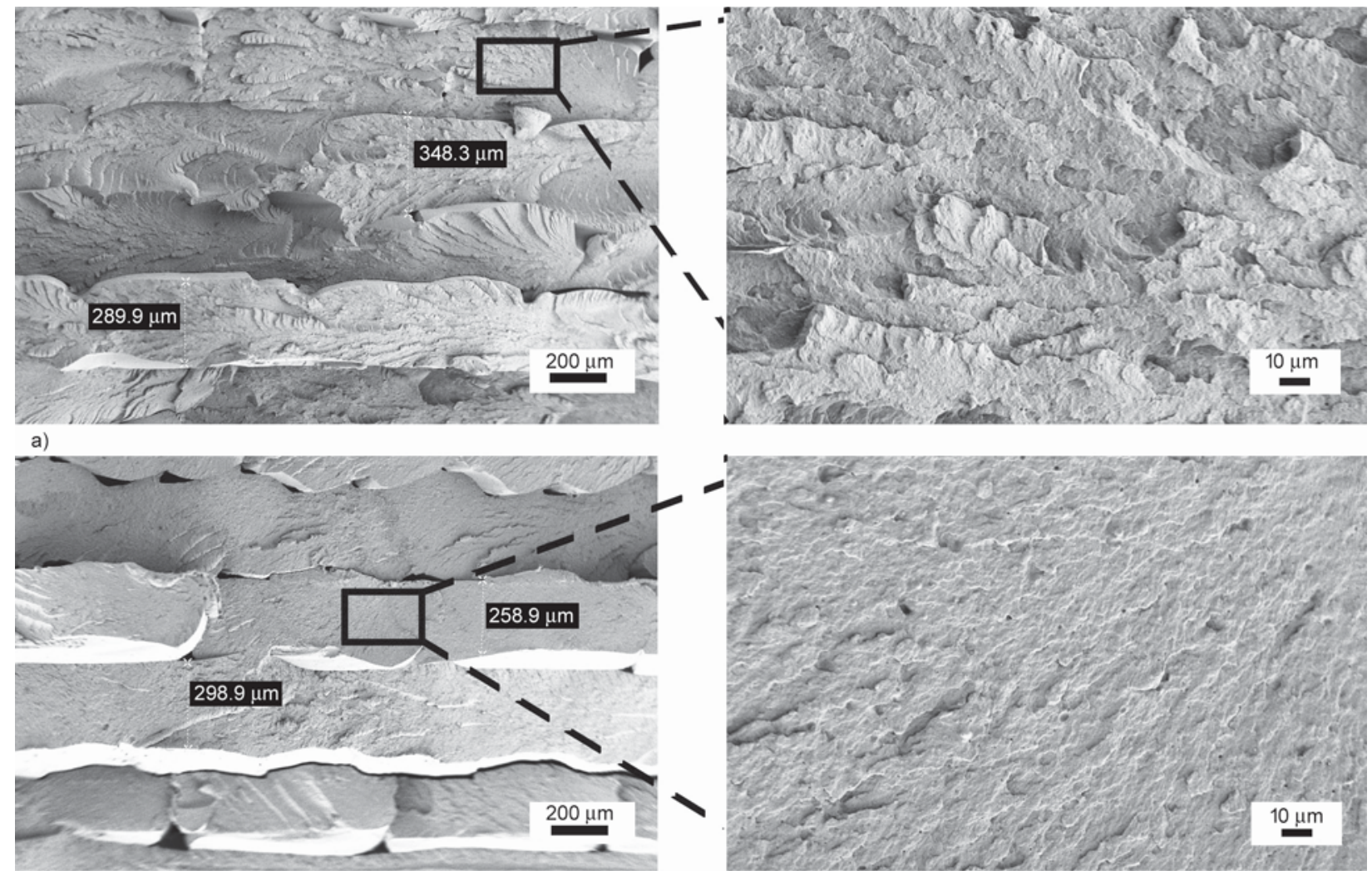

b)

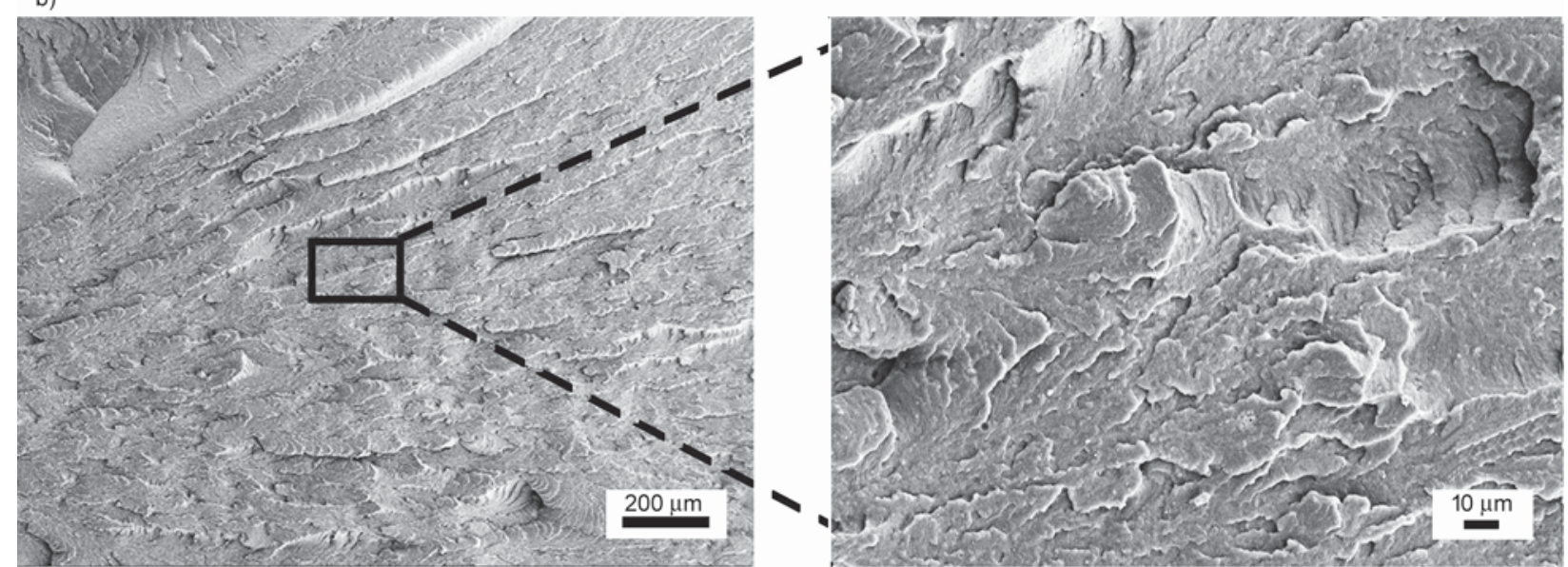

c)
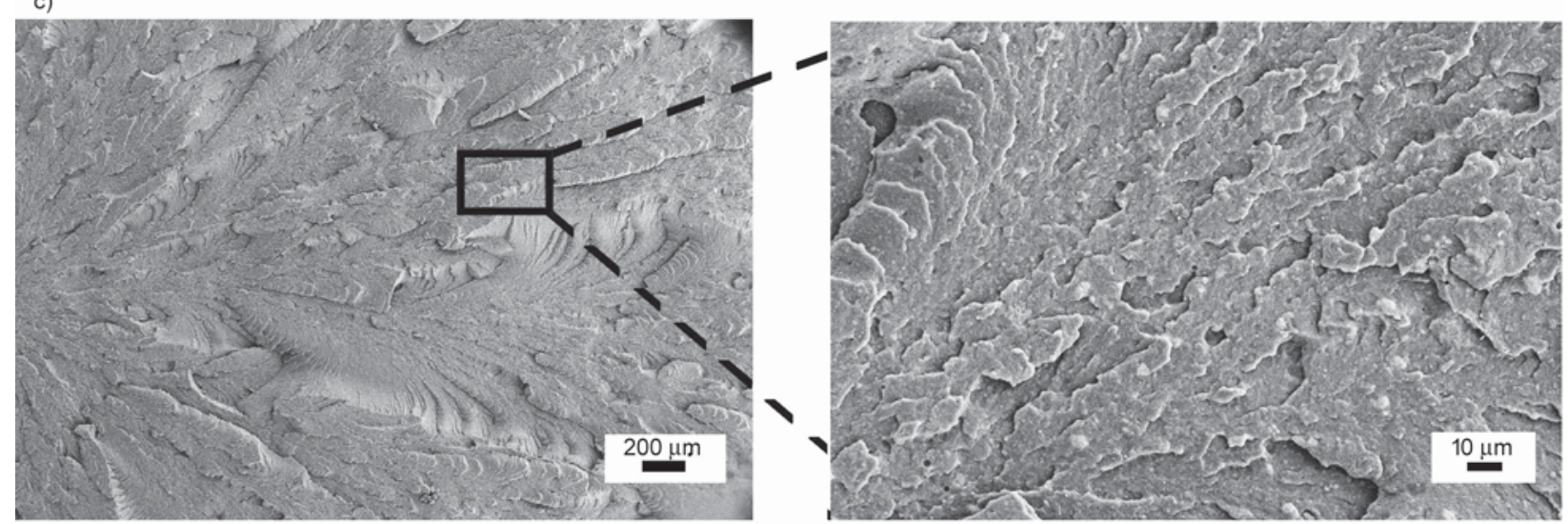

d)

Figure 5. FESEM micrographs of fractured surfaces of $(a, b)$ printed and $(c, d)$ injection moulded of polyamide composites at $10 \mathrm{wt} \%$ (a, c) and $30 \mathrm{wt} \%,(\mathrm{~b}, \mathrm{~d})$ filler loading. Left images display the difference of structural morphology between FDM technique samples $(\mathrm{a}, \mathrm{b})$ and injection moulded samples $(\mathrm{c}, \mathrm{d})$ at low magnification $(50 \times)$, while the right images reflect the highlighted area in the left images with higher magnification $(500 \times)$, providing information on failure mechanism. 
material structure, less porosities which resulting in higher mechanical properties. Despite the excellent structural and performances exhibited by injection moulding technique, the inability of product customisation limits the use of IM technique primarily for large scale manufacturing due to the high costs of tooling and moulds.

As shown in Figure 4a, the tensile strength of the FDM samples did not vary greatly as the filler loading increased up to $30 \mathrm{wt} \%$. Meanwhile, a sharp decline in tensile strength was only observed after it was filled with $40 \mathrm{wt} \%$ fillers. Compared to injection moulded samples, the tensile strength of IM samples appears to increase with the increase in filler content until $20 \mathrm{wt} \%$. Afterwards, it will display a marginal decrease at $30-40 \mathrm{wt} \%$ filler percentages. The improvement of about $12-17 \%$ for IM samples is attributed to the reinforcement effect and fine dispersion between polymer matrix and fillers. Strength improvements were also achieved through the chemical bonding taking place between the hydroxyapatite and polyamide. This interaction can be further proven by evaluating the changes in the FTIR spectra that exist between PA12, HA, and the respective PA12 composites. The difference in the tensile strengths of the FDM and IM samples likely stems from the previously explained differences in their microstructure. Although no improvement was observed, the strength of printed polyamide composites did not exhibit the same pattern as that of the previously reported pattern for the printed ABS composite [12]. Furthermore, its tensile strength was reduced by $25 \%$ after being filled with only $10 \mathrm{wt} \%$ of iron particles. Similarly, another study also reported a significant reduction in strength $(42 \%)$ after incorporation with $30 \mathrm{wt} \%$ copper with ABS [10]. This implies that polyamide matrix with loading of fillers $(10-30 \mathrm{wt} \%)$ is still capable of resisting the stress exerted despite an increase in the number and size of voids in the microstructure of FDM parts. For printed PA12 composites filled at $40 \mathrm{wt} \%$, a decrease in tensile strength is probably due to the ineffective stress transfer from resin matrix to fillers. This transfer leads to catastrophic failure and lowers the yield strength.

Figure 6 shows the broad absorption peak of hydroxyl $(\mathrm{OH})$ at $3436 \mathrm{~cm}^{-1}$, along with a weaker peak formed at $631 \mathrm{~cm}^{-1}$. Compared to the IR spectrum of the composite, these two peaks eventually disappeared in the PA1 2 composites. If this is the case, it can be argued that it is related to the formation of

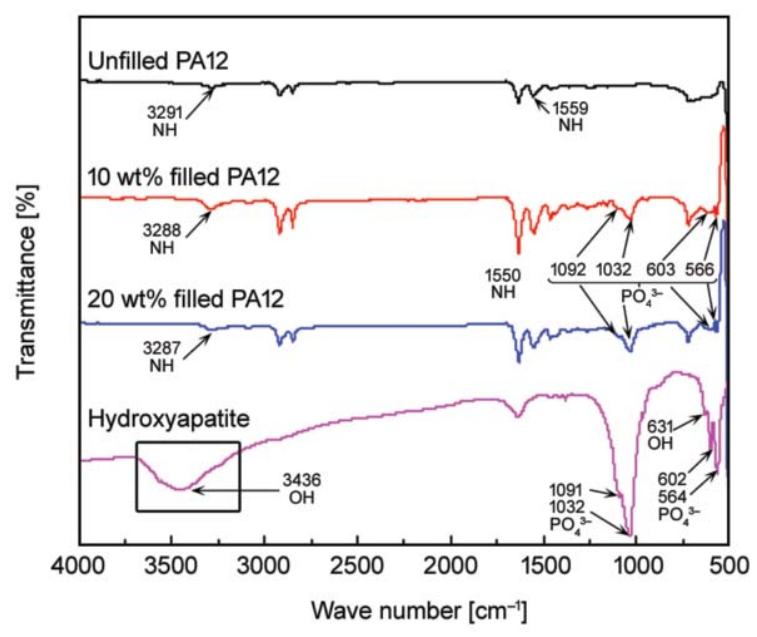

Figure 6. IR spectra of pure PA12, $10 \mathrm{wt} \%$ filled PA12, $20 \mathrm{wt} \%$ filled PA12 and hydroxyapatite

chemical bonding since no - $\mathrm{OH}$ peak was observed in the composites. It could also be due to the fact that the low concentration of HA is hardly detectable using the IR spectrometer. However, it would be rash to conclude such from this statement since the peaks of $\mathrm{PO}_{4}{ }^{3-}$ at $1091,1032,564$ and $602 \mathrm{~cm}^{-1}$ could still be detected in both hydroxyapatite and polyamide composites. Moreover, no obvious changes have been detected for the vibration frequency, indicating that no interaction took place between $\mathrm{PO}_{4}{ }^{3-}$ and any functional group in PA12. Additionally, the peak of the -NH group of polyamides, located at 3291 and $1559 \mathrm{~cm}^{-1}$ shifted down to a lower frequency at 3288 and $1550 \mathrm{~cm}^{-1}$, respectively. Hence, we can say that participation of $-\mathrm{OH}$ and $-\mathrm{NH}$ forming hydrogen bonding would significantly drop the intensity of $-\mathrm{OH}$ group vibration wave number, resulting in the nondetection of -OH in the composite. The same IR spectra were also observed by [23, 38-40] for highly filled PA composites. From the results obtained, it is certainly possible for hydrogen bonding to exist between the - $\mathrm{OH}$ group in $\mathrm{HA}$ and the $-\mathrm{NH}$ of PA12. The bonding may exist as a result of the attractive force between an amide hydrogen and an electronegative oxygen of the - $\mathrm{OH}$ group or between a hydrogen of $-\mathrm{OH}$ to the nitrogen atom of the amide group, as shown in Figure 7. However, the occurrence of the latter is probably easier due to the higher electronegativity of oxygen in -OH compared to that of the nitrogen atom in the amide group [38]. This molecular interaction could play a pivotal role in enabling stress transfer to occur within HA and PA12. This could potentially result in improvements in the mechanical properties of the composites. Meanwhile, the peaks 

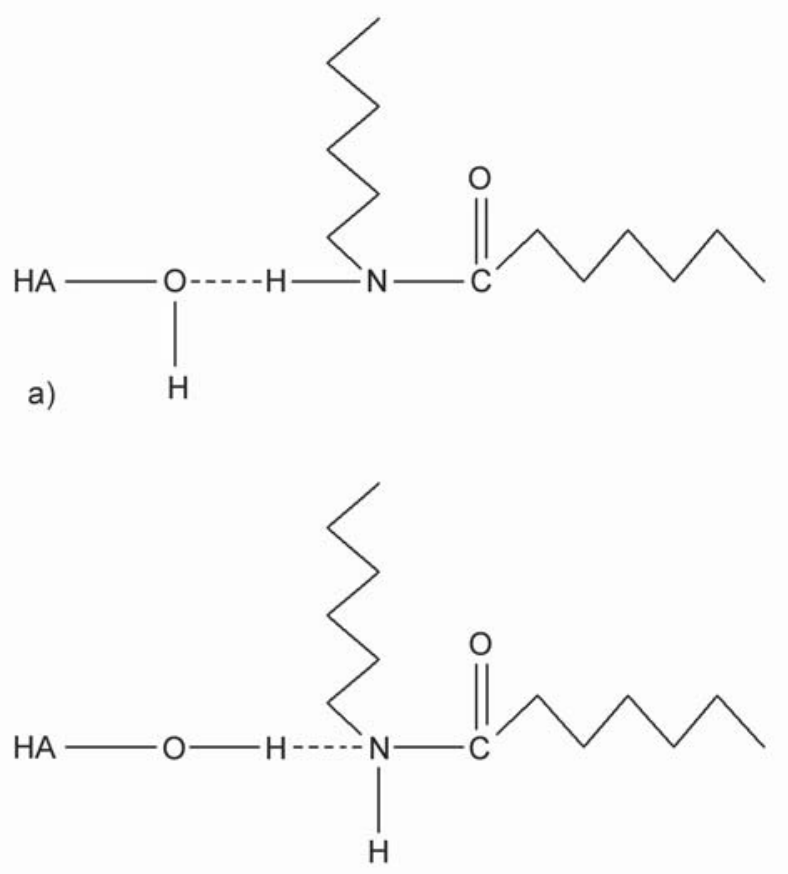

b)

Figure 7. Presumed hydrogen bonding that may exist between -OH group of hydroxyapatite and amide group (-NHCO) of PA12 matrix, a) hydrogen of amide group and oxygen of $-\mathrm{OH}, \mathrm{b}$ ) hydrogen of $-\mathrm{OH}$ and nitrogen of amide group

ascribed to the $-\mathrm{C}=\mathrm{O}$ and $\mathrm{C}-\mathrm{H}$ groups do not present any obvious displacement, as shown in Figure 6. This suggests that these bending vibrations were hardly altered, indicating that almost no changes have taken place for these groups before and after the compound.

By adopting a relatively low concentration of 0 $20 \mathrm{wt} \%$ filler loading, the strength of the FDM PA12 was reduced by approximately $5-17 \%$ than the IM parts. A continuous reduction in strength was observed above this threshold concentration, due to ineffectual stress transfer from the resin matrix to the fillers, leading to a catastrophic failure. Also, incorporation of high filler content would significantly increase the shear viscosity of PA12 melt, thereby lowering the wetting adhesion between the thread lines during consolidation process. As shown in Figure 5b, the thread lines of highly filled PA12 composite appeared to be more visible, with increased the size and the number of remaining gaps in-between as compared to those of low filled composite (refer Figure 5a). Therefore, minimising the gaps between the thread lines is crucial to obtain a satisfactory performance of the FDM part. Comparing the mechanical performance between the FDM PA12 and FDM ABS, the majority of stud- ies reported a reduction of strength [1, 4, 6, 21], after incorporated with fillers, albeit at much lower percentages. The improvement in mechanical properties of the FDM parts can typically be observed when the nano-sized fillers or fibres, were incorporated into the polymer matrix system $[4,9,42,43]$.

\subsubsection{Elastic modulus}

A similar trend was observed for an elastic modulus where the modulus of printed PA12 was even lower (5-24\%) as compared to the IM PA12 at $0-20 \mathrm{wt} \%$ filler loading (refer Figure $4 \mathrm{~b}$ ). In determining the effect of filler content, the modulus or stiffness of both the IM and FDM PA12 increased steadily with a given percentage of filler. However, the modulus of printed PA12 exhibited an increase only after being filled with fillers up to $15 \mathrm{wt} \%$. Afterwards, a modulus of approximately $10 \mathrm{MPa}$ was maintained despite the addition of fillers.

In fact, the trend of the modulus from the FDM samples contradicted with the predicted hypothesis used in this study, by not following the conventional polymer composite system. This was like what has been obtained for the injection moulded specimen. Theoretically, the mechanism leading to a change in the modulus of the material is related to the effectiveness of the load transfer from the polymer matrix to the filler. Nevertheless, this raises an awkward question for FDM part. This is because the efficiency of the load to be transferred from the matrix to the filler in the part composed of multiple layers, with each layer possessing multiple threads and in different orientations is apparently unpredictable and will response in different ways compared with conventional system. In this case, it is assumed that the heterogeneous microstructure of the FDM part, in addition to the uncontrolled gaps existing between the threads, may limit stress transfer from the polymer to the filler, resulting in a reduction of modulus at a particular filler loading. Ning et al. [8] also reported a similar observation. Furthermore, the relatively large standard deviations of modulus were observed after the incorporation of high amounts of fillers (30-40 wt \%). This might be due to of the increase in void formation due to difficulties during the printing process of highly viscous polyamide composites. Consequently, the effect of stiffness that is exhibited by the fillers is counterbalanced with its stress concentration near the voids, resulting in no observable increments in the modulus for the FDM part. 


\subsubsection{Strain at break}

According to Figure 4c, there was a significant decrease in the percentage of the strain at the break after incorporating the fillers, due to the disruption and rearrangement of the polymer chain. Even worse, the maximum strain for all printed PA specimens was reduced to $50-97 \%$ in comparison to the injection moulded specimens. As previously discussed, the FDM printed part is built from multiple layers in which the cooled thread, at the bottom layer, is bonded or 'welded' with a hot thread coming out from the nozzle. By considering an underlying layer is repeatedly in contact with the heat-flowable layer, stress concentrations would develop along the layer-layer interface, leading to further development of delamination and the FDM sample tended to break earlier with a brittle mode fracture. Moreover, the transverse strength of some layers, which were printed perpendicular to the applied stress, was relatively poorer than other directions, resulting in a lower elongation at break.

\subsubsection{Toughness and impact strength}

Utilizing the stress-strain curve, the area underneath was measured to obtain the toughness of the sample, which is referred to as the energy absorption per unit volume of material. Following the pattern as obtained for maximum strain, the neat injection moulded PA12 was considered to be the toughest material. However, the addition of fillers significantly decreased the toughness of the sample and there were substantial loses after FDM processing (refer Figure 4d). This indicates that with the addition of fillers and the FDM technique, this will potentially cause

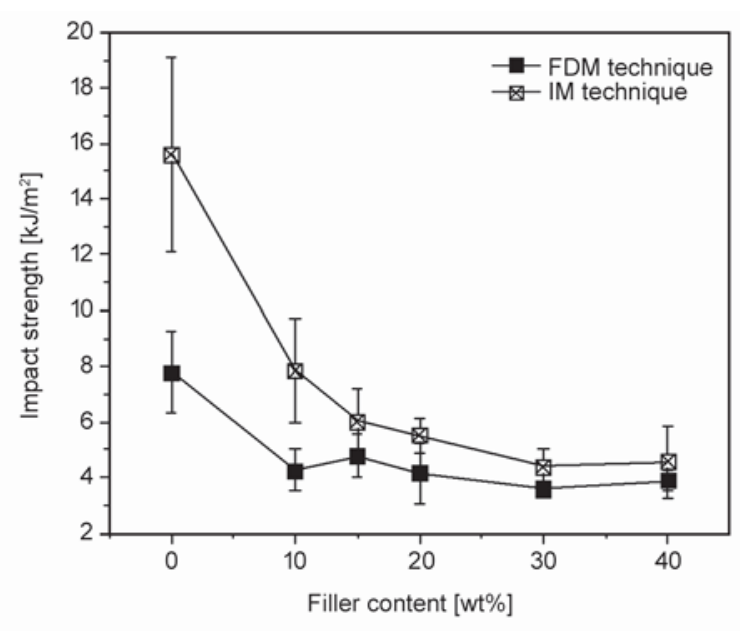

Figure 8. Impact strength of printed and injection moulded of pure PA12 and PA12 composites filled $10-40 \mathrm{wt} \%$ filler loading

the transition of ductile-to-brittle occurring in PA12, as explained previously. Again, a similar trend was observed for the impact strength of printed polyamide composites in comparison to injection moulded PA12 composites, as shown in Figure 8.

\subsubsection{Flexural properties}

The flexural strength and flexural modulus of FDM and IM specimens are shown in Figure 9. Both flexural strength and flexural modulus of PA12 increased with the amount of fillers being incorporated, but with more noticeable improvements in the injection moulded samples. The highest flexural strength and modulus were acquired at the largest filled PA12 composite ( $40 \mathrm{wt} \%$ filler loading) which was around 52.3 and $1557 \mathrm{MPa}$, respectively. It is noted that the trend of flexural properties was in stark contrast to the

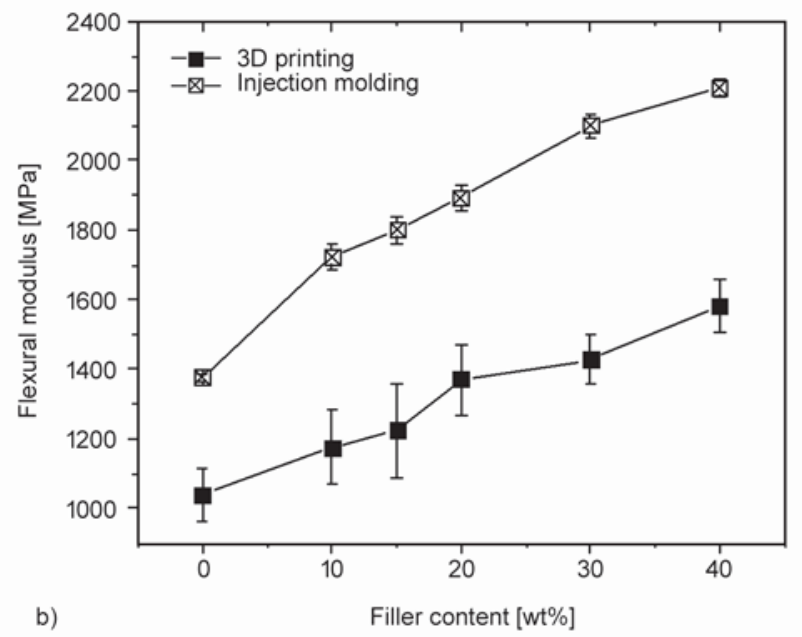

Figure 9. Flexural properties of printed and injection moulded of pure PA12 and PA12 composites filled $10-40 \mathrm{wt} \%$ filler loading, a) flexural strength at yield, b) flexural modulus 
aforementioned tensile properties, particularly at the higher filler content.

The most likely explanation for the disparity between these results might be attributed to the difference in the type of stresses created in the sample during loading. During flexural loading, the compressive stresses generated in the material contributed in reducing the size of the air gaps and microvoids that were formed. This was in contrast to the crack opening mechanism that occurred during the tensile condition. Figure 10 illustrates the difference between the direction of stress occurring during the tensile and flexural test. Therefore, the flexural strength was greater than the tensile strength of similar samples, and yet, the increase in strength can be observed for the composites until incorporating $40 \mathrm{wt} \%$ fillers.

From all the results of mechanical properties, marked variations were identified in the mechanical behaviour of the PA12 due to the different techniques carried out and the filler loadings. The predominant material failure involved in the FDM technique was a result of poor bond adhesion existing from layer-tolayer. Layer printing creates potentially weak areas at each layer; causing the strength of the printed part to lag behind the same part manufactured using injection moulding. During FDM printing, when the material was extruded out and deposited to build a layer, the material was quickly solidified, becoming hard. The subsequent layer, remaining hot, would fuse together with the previous layer and the process continuing until all layers of the part were completed. The consolidation of the hot layer, into a solid layer, may potentially result in poor interfacial bonding

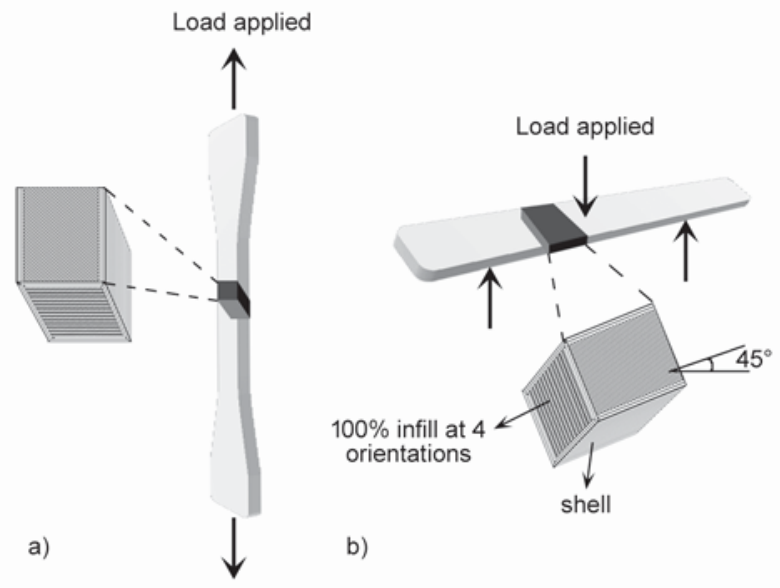

Figure 10. Overview of printed (a) tensile and (b) flexural samples, with details on infill orientation, shells, cross section of main dimension and the direction of force during the tests existing between the layers and significantly weakening the structural integrity of the part thereby, affecting the strength of the product. Although not possible to eliminate the laminate weakness or compete against injection moulding, the printed parts can be created sufficiently stronger by applying the correct processing parameters and minimising any gaps that may exist between the layers and threads. Also, by introducing reinforcing fillers, (i. e. zirconia and HA), the disparity of mechanical properties between FDM and IM may be reduced.

When considering a material for human implantation, a material characterised by high strength and high strain to failure is preferred to avoid potential tragic and consequential failure inside the human body. From the literature, there appears no minimum requirement or standard currently available for the mechanical properties associated with implant materials. Usually, researchers refer to the mechanical properties of the cortical bone and cancellous bone which exhibit a strength of 35-283 and 1.5-38 MPa, respectively. While the properties of human bones are considered as being a 'gold' standard for implant materials, the strength of commercial polymer-based implants varies, ranging from $20-140 \mathrm{MPa}[36,37] \mathrm{de}-$ pending on the implant areas of the human anatomy. From the results obtained, the strength of printed PA composites far exceeds the strength of cancellous bone and reaching the lower range of a cortical bone's strength. Therefore, the properties of printed the PA composite may not adequately sustain load-bearing areas of the body. However, the material may be suitable for applying to non-loading areas, such as with orbital floor implants or middle ear prostheses. Overall, PA composites comprising of $10-20 \mathrm{wt} \%$ fillers may show highly promising use as implant materials due to the moderate mechanical properties compared with other compositions.

\subsection{Morphological properties}

Figure 5 represent SEM images of the fractured surface polyamide 12 prepared by FDM and IM. The differences in the pattern morphologies existing between the two techniques are clearly observed. The structure of the 3D printed part having been fabricated using the FDM method was built using a default setting of a $0 / 90 /-45 / 45^{\circ}$ lay-down pattern at $100 \%$ material infill. The filaments were stacked together in both horizontal layer ( $x-y$ direction) and vertical layer ( $z$-direction) in a fabrication process to 
complete a 3D part. The cross-section of the printed part showed the layer height of deposited thread in the $z$-direction, being approximately $0.3 \mathrm{~mm}$ in diameter, and in agreement with the parameter setting. As can be seen in Figure $5 a-5 b$, all the threads of polyamide composites were merged with one another. This is in contrast to the most reported FDM materials, i. e. ABS and PLA, where the threads or filaments are usually separated, leaving an internal pore structure between the thread lines $[41,44]$. This may be due to the high percentage of infill (100\%), in addition to the lower viscosity of polymer melt finally contacting the threads to each other, filling the air gap and reducing the percentage of porosity. Rocha et al. [45] observed the same morphology of ABS after incorporating with a low melt viscosity of polymeric elastomer. However, in case of higher melt viscosity of $30 \mathrm{wt} \%$ filled PA12 (Figure $5 \mathrm{~b}$ ), the thread can be observed at certain regions as a grooved layer with air gap in between. In case of injection moulded parts, a continuous phase of polymer matrix was achieved along with the flow direction under application of high shear.

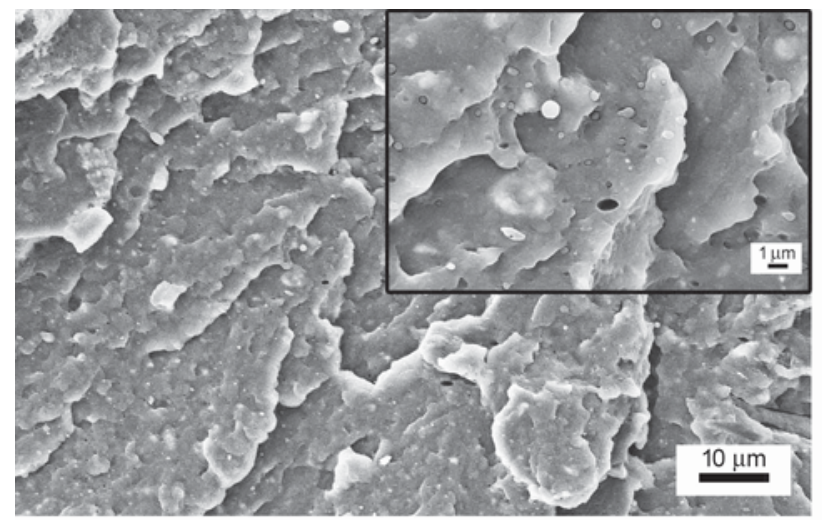

a)

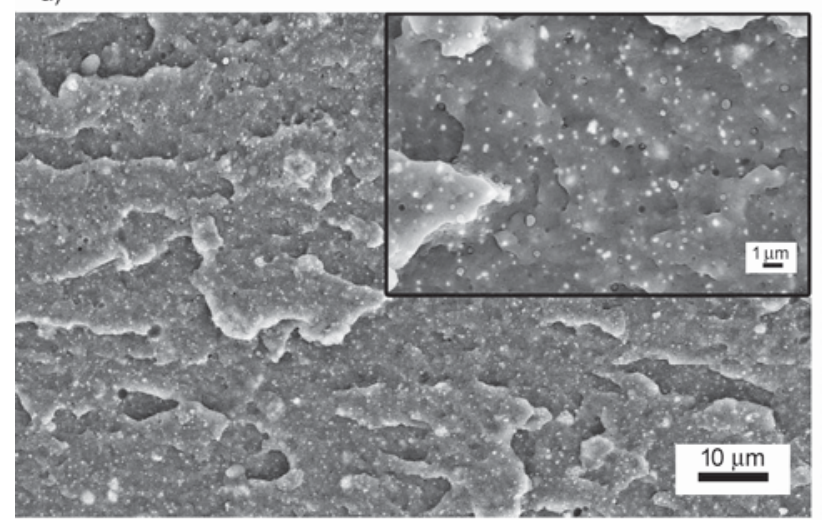

c)
SEM images could provide further insight into determining and comparing the mode of failures existing between using these techniques. The fracture surface of printed $10 \mathrm{wt} \%$ filled PA12 composite (Figure 5a) reveals a coarse texture with shear bands being formed from plastic deformation. The material in the shear band is highly orientated compared to the adjacent region. In contrast, $30 \mathrm{wt} \%$ filled PA12 composite (Figure $5 b$ ) has a very smooth fracture surface, indicating high elastic properties corresponding to brittle failure. In comparison to the injection moulded part (Figure 5c-5d), both PA12 compositions demonstrated similar phase morphology with $10 \mathrm{wt} \%$ filled PA12, showing increased skin and shear layer thickness due to the higher energy required to cause the fracture.

FESEM micrographs of the tensile fractured surface of polyamide composites at selected filler loadings are shown in Figure 11. It was found that the white filler phase was well dispersed in the black polyamide matrix. Furthermore, more compactness was observed when the filler content is increased, leading to improvements in the mechanical properties of

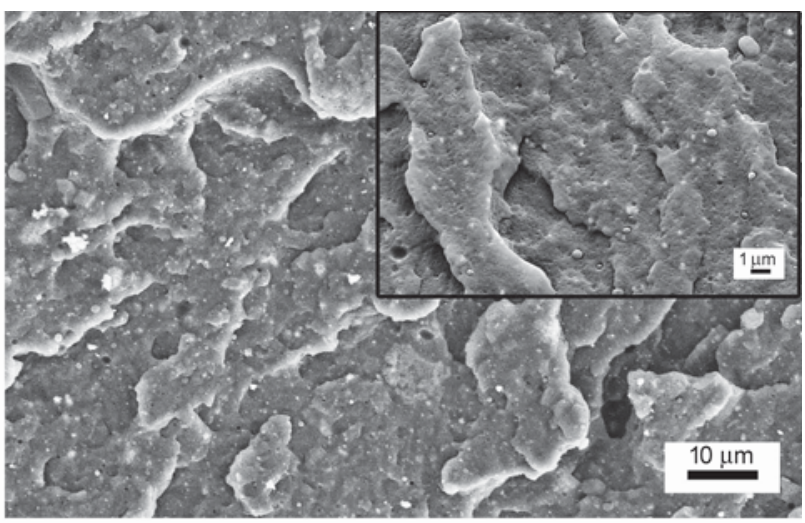

b)

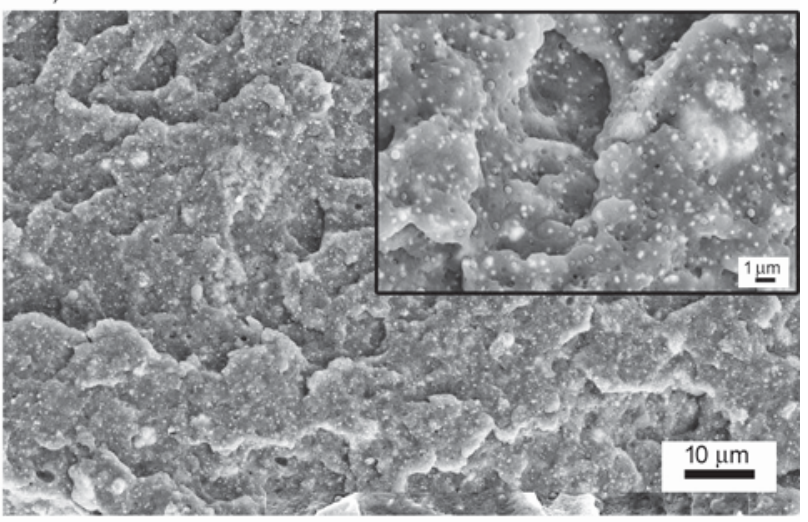

d)

Figure 11. Fractured surface of PA12 composite filled with (a) $10 \mathrm{wt} \%$, (b) $20 \mathrm{wt} \%$, (c) $30 \mathrm{wt} \%$, and (d) $40 \mathrm{wt} \%$ filler content at $1000 \times$ magnification. The inset is a high magnification $(5000 \times)$ micrograph showing the distribution of fillers within the polyamide matrix. 
injection moulded samples and improvements in the flexural properties of printed samples. However, in the case of tensile properties, the strengthening effect of polyamide composites must compensate for the crack propagation in the polymer matrix. Thus, only an increase in modulus at low filler percentage was observed, with no changes for tensile strength.

To identify the filler type within the polymer matrix, a representation of the PA composite using a high magnification was obtained. This is shown in Figure 12. The micrograph depicts the zirconia particles appeared brighter than hydroxyapatite due to the difference in their atomic number. The presence of zirconium and oxygen content from performing the EDX analysis, confirmed the zirconia filler image, while hydroxylapatite fillers represented the calcium, oxygen and phosphorus elements. As seen from the figure, hydroxyapatite fillers were depicted as spherical in structure. These fillers were formed by the agglomeration of individual, small HA particles. In general, inorganic fillers tend to bundle together due to the attractive forces stemming from Van der Waals interactions, leading to the formation of agglomerated particles [46]. The exposure of large agglomerations of hydroxyapatite shows that the filler-matrix adhesion is relatively weak, thereby allowing fillermatrix debonding to occur quickly, especially if the filler content is high. In the case of zirconia, although agglomeration of zirconia fillers was observed at certain locations, the majority appeared in the polymer matrix, as shown in Figure 12. The bonding force existing between the zirconia and polyamide matrix is predominantly caused by physical interactions occurring as compared to chemical bonding between

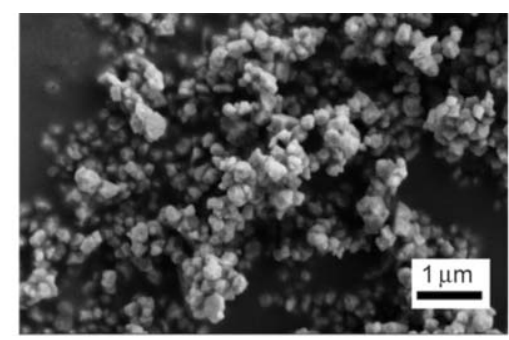

a)

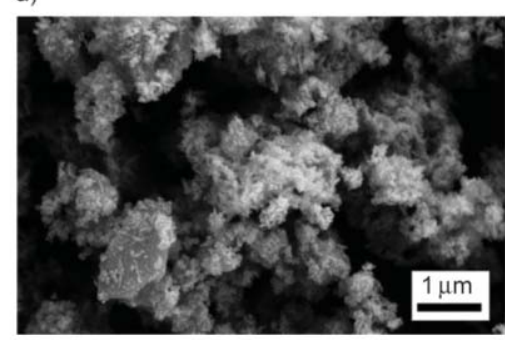

b)

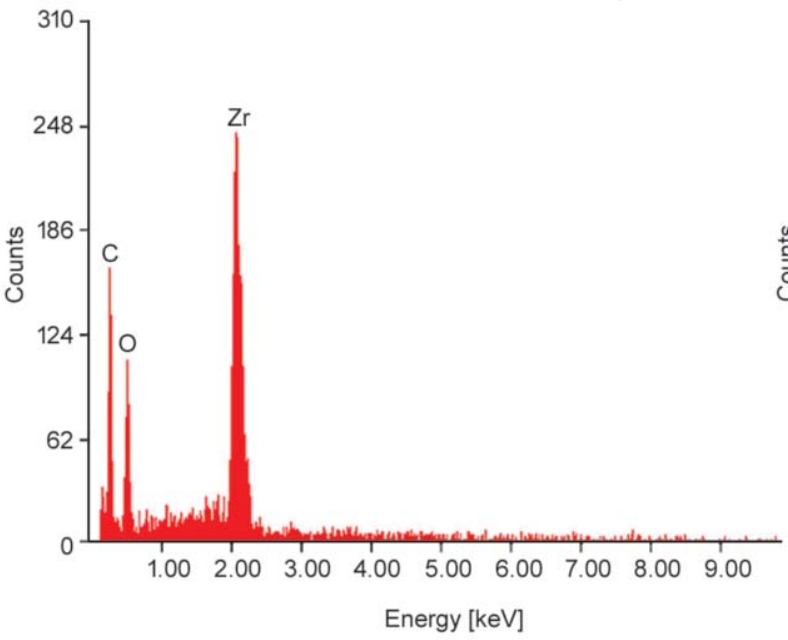

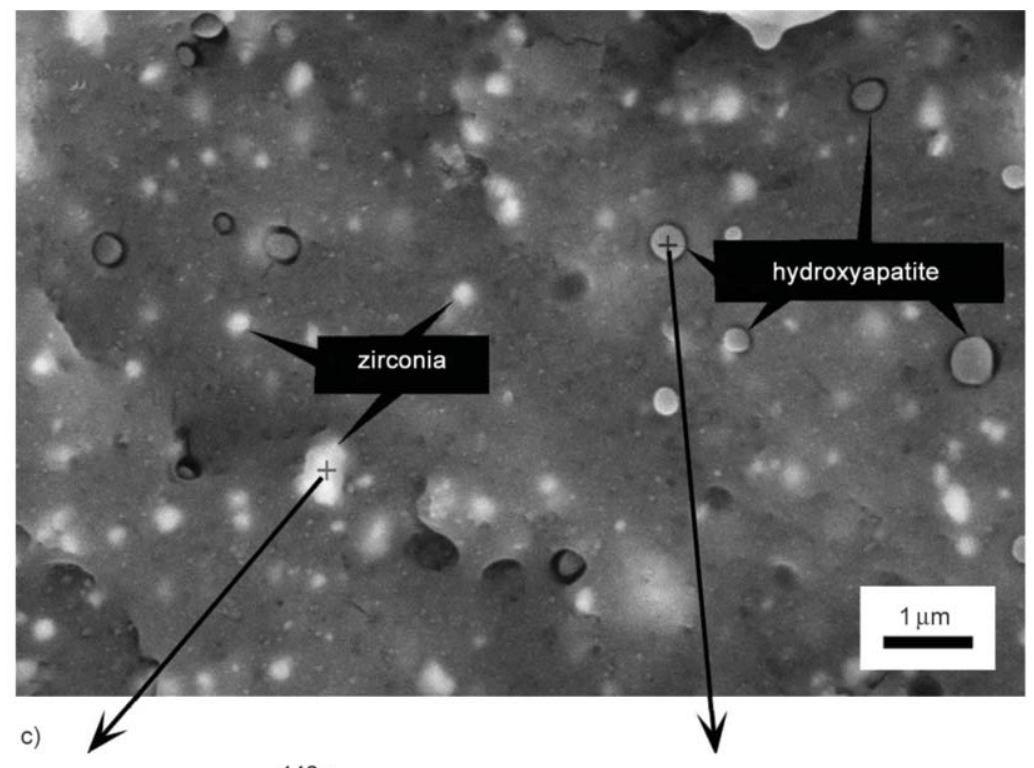

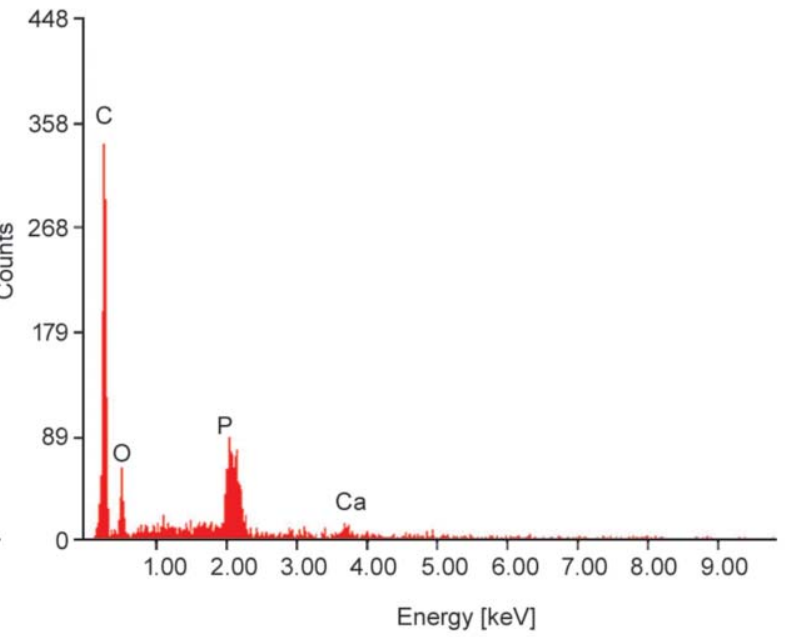

Figure 12. FESEM micrographs of (a) zirconia and (b) hydroxyapatite fillers at $15000 \times$ magnification. The filler distribution in the PA12 composite at $30 \mathrm{wt} \%$ filler loading is shown in (c) at $10000 \times$ magnification, along with a single point EDX measurement at agglomerated filler particles. 
the hydroxyapatite and polyamide matrix. This observation indicates that zirconia fillers play an essential role to increase the strength of the polymer composite system.

\subsection{Thermal properties}

\subsubsection{Differential scanning calorimetry analysis}

Figure 13 shows the thermogram of PA12 composites during the first and second heating scans performed. The measurement was carried out to the pellet-form and the cut-off printed specimens. As was observed, the thermogram of printed specimens revealed the same pattern as the pellet specimen during the first and second heating. This confirmed that the thermal properties for both conditions were approximately similar. However, the pattern was, in fact, different when comparing to the first and second scan. With the first heating scan, the polyamide displayed a typical curve that indicates a slight recrystallization and a subsequent melting peak. While, the curve from second heating showed a dual peak, suggesting a sequence of melting behaviour due to the presence of a different crystalline structure in the polyamide. This circumstance might be due to the polyamide behaviour in nature that can adopts a different crystal structures, also known as polymorphism. In agreement with our results, some previous studies [47, 48] also reported the similar patterns as obtained.

Polyamide 12 is capable of producing $\alpha$ - and $\gamma$-formed crystals. The capabilities of polyamide 12 to produce these crystals, occurs when hydrogen bonding in the crystal takes place either in parallel or antiparallel fashions (refer Figure 14). However, it is well documented, that the dominant crystalline phase in polyamide 12 is represented by $\gamma$-form crystals [49-51].

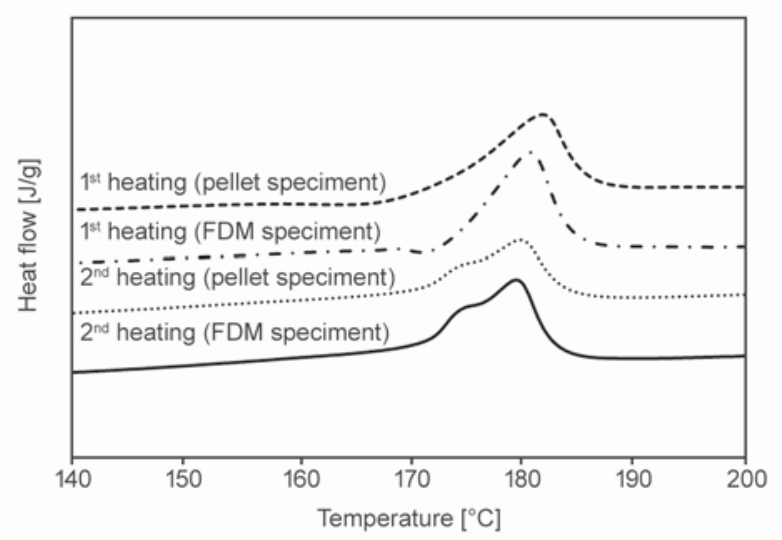

Figure 13. Melting curves of representative of PA12 composite in pellet-form and printed specimen, $1^{\text {st }}$ heating and $2^{\text {nd }}$ heating scan at $10^{\circ} \mathrm{C} / \mathrm{min}$
To create $\gamma$-form crystals polymer chains should be aligned and oriented antiparallel to each other (Figure $14 \mathrm{~b}$ ), to form hydrogen bonding rather than appearing in a parallel arrangement (Figure 14a). Concerning the first heating scan, polyamide exhibited a single melting peak with a relatively higher $\Delta H_{\mathrm{f}}$ and $T_{\mathrm{m}}$, suggesting the presence of $\gamma$-form crystals due to the higher energy required to break the larger amount of hydrogen bonds existing in a crystalline fraction. In comparison with the thermogram on the second heating, it was noticeable that the appearance of the shoulder peak on the left side of the current peak showed a presence of another crystalline structure in polyamide, which could be associated with the formation of $\alpha$-form crystals. The difference may be attributed to the cooling rate, as pelletised and printed samples were rapidly cooled down to ambient room temperature, whereas the re-melted samples were subjected to a slower cooling rate $\left(10^{\circ} \mathrm{C} / \mathrm{min}\right)$ during cold crystallisation using DSC equipment. It is proposed that polymer chains which experience a low cooling rate are inclined to organise and orientate in a parallel fashion (Figure 14a), rather than in an antiparallel fashion, resulting in only half the bonds being made from polyamide chains. Therefore, from the results, it can be concluded that the polymorphic behaviour of PA12 is strongly dependent on the thermal history and the applied cooling rate.

Table 3, shows the $T_{\mathrm{m}}, \Delta H_{\mathrm{f}}$ and the degree of crystallinity $\left(X_{\mathrm{c}}\right)$, of pelletised and printed polyamide
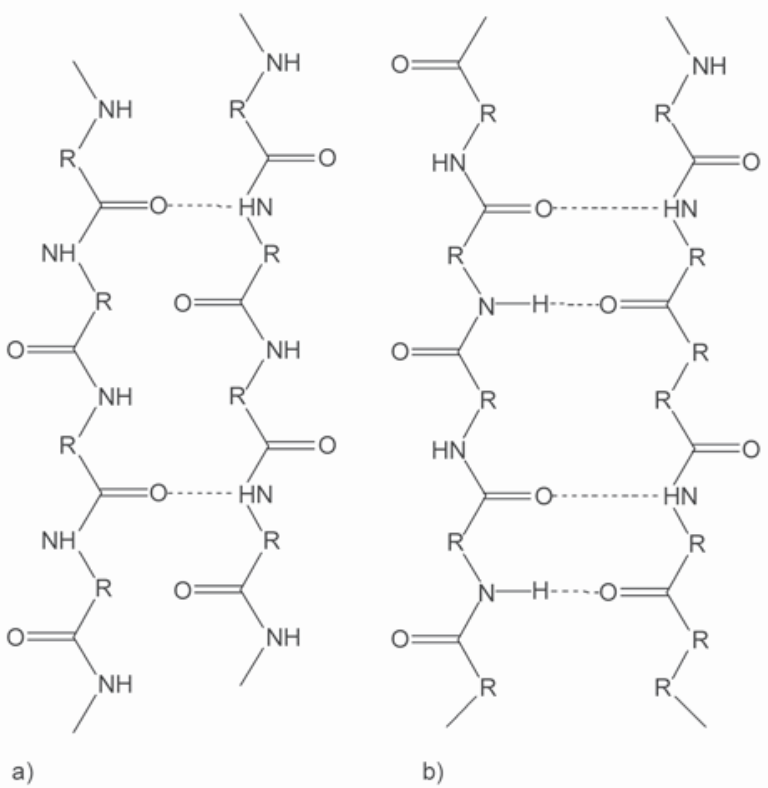

b)

Figure 14. Illustration of polyamide 12 chain in the (a) parallel and (b) antiparallel orientation with possible consumption of hydrogen bonds 
Table 3. DSC data of PA12 and PA12 composites (pellet and printed) comparing the $T_{\mathrm{m}}, \Delta H_{\mathrm{f}}$ and $X_{\mathrm{c}}$ taken from the first and second heating ramps

\begin{tabular}{|c|c|c|c|c|c|c|}
\hline \multirow[b]{2}{*}{ Sample } & \multicolumn{3}{|c|}{ First heating } & \multicolumn{3}{|c|}{ Second heating } \\
\hline & $\begin{array}{c}T_{\mathrm{m}} \\
{\left[{ }^{\circ} \mathbf{C}\right]}\end{array}$ & $\begin{array}{c}\Delta \boldsymbol{H}_{\mathbf{f}} \\
{[\mathbf{J} / \mathbf{g}]}\end{array}$ & $\begin{array}{c}X_{\mathrm{c}} \\
{[\%]}\end{array}$ & $\begin{array}{c}T_{\mathrm{m}} \\
{\left[{ }^{\circ} \mathbf{C}\right]}\end{array}$ & $\begin{array}{l}\Delta \boldsymbol{H}_{\mathbf{f}} \\
{[\mathbf{J} / \mathbf{g}]}\end{array}$ & $\begin{array}{c}X_{\mathrm{c}} \\
{[\%]}\end{array}$ \\
\hline \multicolumn{7}{|c|}{ Pelletized PA12 } \\
\hline PA $12(100)$ & 183.33 & 33.98 & 16.24 & 181.09 & 19.98 & 9.55 \\
\hline $\mathrm{PA} 12 / \mathrm{ZrO}_{2} / \mathrm{HA}(90 / 0 / 10)$ & 181.95 & 23.32 & 12.38 & 179.50 & 16.31 & 8.66 \\
\hline $\mathrm{PA} 12 / \mathrm{ZrO}_{2} / \mathrm{HA}(85 / 5 / 10)$ & 181.20 & 20.79 & 11.69 & 178.18 & 16.30 & 9.16 \\
\hline $\mathrm{PA} 12 / \mathrm{ZrO}_{2} / \mathrm{HA}(80 / 10 / 10)$ & 181.89 & 22.85 & 13.65 & 179.98 & 16.65 & 9.94 \\
\hline $\mathrm{PA} 12 / \mathrm{ZrO}_{2} / \mathrm{HA}(70 / 20 / 10)$ & 180.48 & 22.24 & 15.18 & 178.99 & 17.90 & 12.22 \\
\hline $\mathrm{PA} 12 / \mathrm{ZrO}_{2} / \mathrm{HA}(60 / 30 / 10)$ & 180.99 & 19.18 & 15.27 & 179.78 & 15.99 & 12.73 \\
\hline \multicolumn{7}{|c|}{ Printed PA12 } \\
\hline PA $12(100)$ & 184.25 & 28.52 & 13.63 & 180.80 & 19.47 & 9.30 \\
\hline $\mathrm{PA} 12 / \mathrm{ZrO}_{2} / \mathrm{HA}(90 / 0 / 10)$ & 183.10 & 14.95 & 7.94 & 180.17 & 13.98 & 7.42 \\
\hline $\mathrm{PA} 12 / \mathrm{ZrO}_{2} / \mathrm{HA}(85 / 5 / 10)$ & 182.84 & 23.08 & 12.97 & 179.72 & 21.31 & 11.98 \\
\hline $\mathrm{PA} 12 / \mathrm{ZrO}_{2} / \mathrm{HA}(80 / 10 / 10)$ & 181.97 & 20.29 & 12.12 & 178.98 & 19.18 & 11.45 \\
\hline $\mathrm{PA} 12 / \mathrm{ZrO}_{2} / \mathrm{HA}(70 / 20 / 10)$ & 182.43 & 17.14 & 11.70 & 180.11 & 16.19 & 11.05 \\
\hline $\mathrm{PA} 12 / \mathrm{ZrO}_{2} / \mathrm{HA}(60 / 30 / 10)$ & 181.55 & 14.56 & 11.59 & 179.98 & 14.34 & 11.42 \\
\hline
\end{tabular}

contemplated on the second heating scan. All $T_{\mathrm{m}}$ of the polyamide composites showed a slight reduction as compared to neat polyamide. This suggests that the incorporation of fillers restricts the mobility of polymer chains, thereby promoting the formation of smaller, disordered crystallites, and eventually reducing temperatures $\left(T_{\mathrm{m}}\right)$ at which point, the largest crystallites will disappear. From the results obtained, the effect of filler concentrations on melting temperatures identified the values being consistently scattered for all composite systems. The melting temperature of the highest filler concentration ( $40 \mathrm{wt} \%$ ) was almost like the lower concentrations (10-20 wt \%). Thus, the melting temperature was not severely affected by the volume of fillers. A similar effect of filler content on $T_{\mathrm{m}}$ was also reported by Zhou et al. [20], for PA6, filled with hydroxyapatite.

Table 3 also shows the enthalpy of fusion $\left(\Delta H_{\mathrm{f}}\right)$ and degree of crystallinity $\left(X_{\mathrm{c}}\right)$ of PA12 composites at first and second heating. As previously explained, modification of crystal during crystallization lowers the $T_{\mathrm{m}}$ and $\Delta H_{\mathrm{f}}$ required to melt the matrix. This indirectly affects the degree of crystallinity $\left(X_{\mathrm{c}}\right)$. A significant difference was observed between the $1^{\text {st }}$ and $2^{\text {nd }}$ heating, with a higher value of $X_{c}$ observed during the $1^{\text {st }}$ heating. The higher crystallinity of polyamide that was obtained during first heating could be explained by the arrangement of polymer molecules during the extrusion process. At this stage, polymer chains were orientated towards the flow direction due to the application of high shear stress. These molecular structures remained oriented when they were immediately cooled in water, resulting in high crystallinity and more energy $\Delta H_{\mathrm{f}}$ required to overcome the existing bond between the polymer chains. In contrast to the $X_{\mathrm{c}}$ at $2^{\text {nd }}$ heating, the sample no longer subjected to high pressure, which in turn increased the free volume between the polymer chains and provided more space for the polymer chains to move randomly.

Comparing the values of $X_{\mathrm{c}}$ between all composite systems, no appreciable trend was observed for $1^{\text {st }}$ heating scan, probably due to the influence of shear during processing. However, minimal impact of fillers was detected on the $X_{\mathrm{c}}$ after the $2^{\text {nd }}$ heating. From the results obtained, both fillers provided a contrary effect on the value of $X_{\mathrm{c}}$, (i.e. incorporating hydroxyapatite lowers the $X_{\mathrm{c}}$ while zirconia showed a vice versa effect). The decrease of crystallinity may additionally result from the formation of hydrogen bonds existing between $\mathrm{OH}^{-}$of hydroxyapatite and the amide group of polyamides, limiting the rearrangement of PA12 macromolecules, and at the same time, reducing the number of hydrogen bonds between the polyamide chains. A similar observation was also obtained from a study carried out by Zhang et al. [52] identifying a decrease in PA66 crystallinity due to the presence of hydroxyapatite crystals, impedes the motion of the polymer chain and eventually inhibits PA66 crystal growth. Meanwhile, incorporating zirconia can marginally alter the degree of crystallinity of composites. The small, rounded particles of zirconia afford an efficient packing density, providing a greater uniform filler arrangement in the 
polymer matrix (Figure 12), thereby leading to an increase in $X_{\mathrm{c}}$.

In addition to this, a study by Fornes and Paul (2004) [6] also claimed that the crystallinity of aliphatic polyamide is strongly influenced by the complete consumption of all possible hydrogen bonds to form intermolecular bonding between chains. As previously explained, polyamide 12 may be aligned in a parallel or antiparallel orientation to form $\alpha$ - and $\gamma$ form crystals, respectively. For even polyamides such as polyamide 12 , the highest crystallinity can only be obtained if all polymer chains are oriented in an antiparallel manner. The existence of shoulder peak serves as proof of the partial transformation of the $\gamma$-form crystals structure to the $\alpha$-crystalline modification, which results in lower crystallinity. Basically, $\alpha$-form crystal is thermodynamically stable; howev$\mathrm{er}$, the formation of $\gamma$-crystal is kinetically favoured [7]. Thus, the $\gamma$-form crystal may represent the dominant crystalline phase of PA12. However, the difference in cooling rate may influence the crystal formation of polyamide 12 . A high cooling rate during polymer processing may result in the formation of unstable $\gamma$-crystal. On the other hand, $\alpha$-form crystals are obtained when the polymer is cooled under a controlled and low cooling rate condition. When comparing the results of $X_{\mathrm{c}}$ between pelletised and printed PA12 for the $1^{\text {st }}$ heating scan (Table 3), most of the samples revealed a slight decrease in their degree of crystallinity, indicating that the cooling rate for the printed and pellets PA12 during the process only slightly differed. However, no appreciable differences could be observed after the $2^{\text {nd }}$ heating scan. This confirms that after the thermal history has been

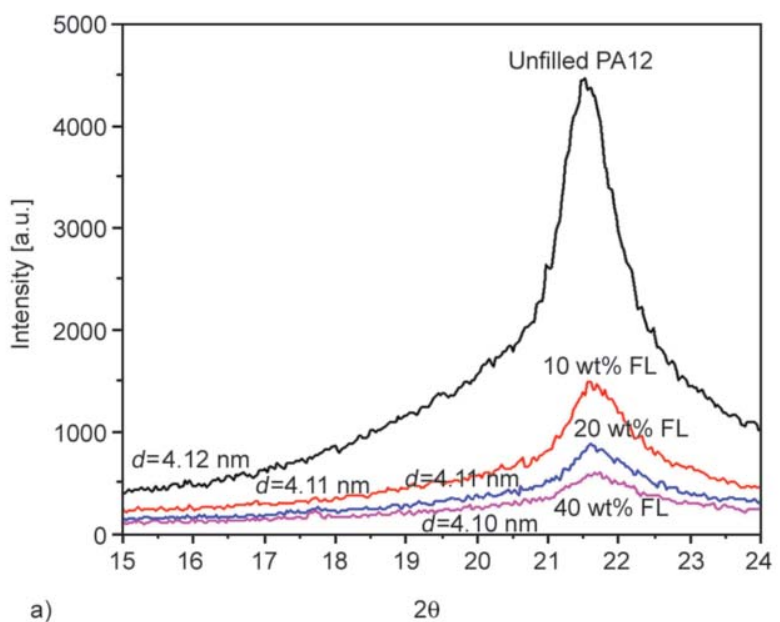

removed during the first heating, both samples went through a similar rate of crystallisation, resulting in the same $X_{\mathrm{c}}$.

\subsubsection{XRD analysis}

XRD analysis was conducted to identify and prove the type of crystals present in polyamide samples, in conjunction with the crystallisation characteristics identified using DSC. Figure 15a illustrates XRD patterns of unfilled PA12 and composites with different filler content, predominant reflections and corresponding $d$-spacings. An intense reflection at $2 \theta=$ 21.6 ( $d$-spacing $\approx 0.41 \mathrm{~nm}$ ) was observed for all material systems, corresponding to the stable $\gamma$-form crystal phase of PA12. With the increase in filler content in the PA12 matrix, the peak intensity of the $\gamma$ crystalline form of PA12 decreased proportionately due to a lower polyamide mass fraction in the composites and destruction of the ordered crystalline structure of PA12.

The effect of processing (injection moulding and FDM process) on crystallisation of PA12 can be analysed further by comparing their diffraction patterns, as shown in Figure 15b. The printed PA12 revealed a strong reflection at $2 \theta=21.6$, similar to what were observed for injection moulded samples. However, the peak intensity of printed PA12 was slightly lower than the IM samples, suggesting the lower crystallinity exhibited by the printed sample, or probably the rougher surface of printed sample might reduce or distort the peak intensity. In the case of PA12 that present $\alpha$-form crystals, there should be two strong adjacent peaks in the diffraction angles of 20-22 [53]. Although no significant reflection corresponds

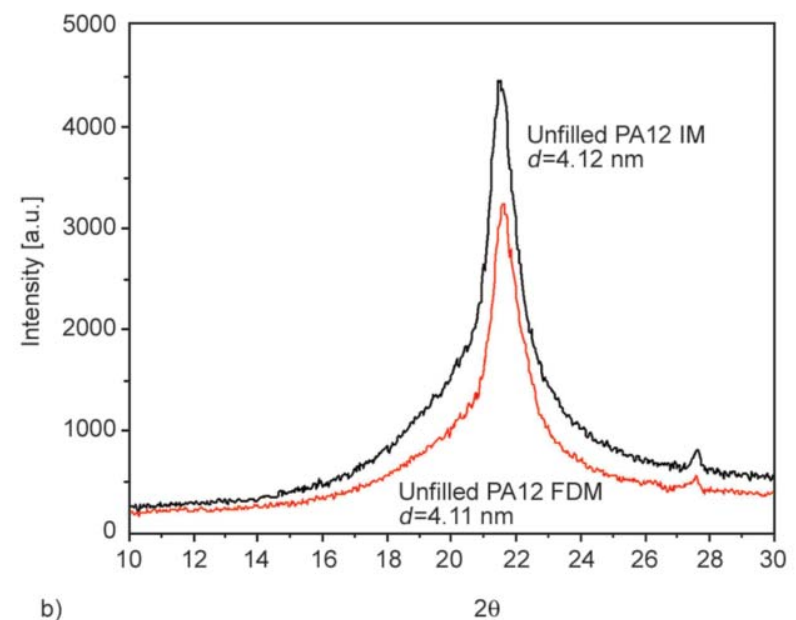

Figure 15. XRD patterns of (a) pure PA12 and PA12 composites at several filler loadings and (b) injection moulded and printed sample of representative PA12 
to $\alpha$-form crystal, all samples exhibited a small bulge in the diffraction pattern at $2 \theta=27.9^{\circ}$, which likely stems from the trace amount of original $\alpha$-crystals that remained un-melted in the final part [53].

XRD and DSC could be used to investigate the effect of processing on the characteristics associated with crystallisation. Based on the results, the presence of one strong reflection and a single melting peak at the first heating, recorded by the XRD and DSC respectively, indicated the presence of a single crystal polymorph, which corresponds to the $\gamma$-form crystal in the processing of the final part. It is assumed that the cooling rate between all processing techniques utilised in this study was not significantly different, resulting in the same crystallisation characteristics, particularly on the crystal type.

\subsubsection{TGA analysis}

Thermal properties obtained from the TG and DTG curves of the pellet's form and the printed parts are listed in Table 4. It was found that polyamides were thermally stable at temperatures below $430^{\circ} \mathrm{C}$, which were much higher than the processing temperatures. The onset temperature $T_{\mathrm{i}}$ was increased after incorporating hydroxyapatite and zirconia, showing the thermal stability of polyamide improving after incorporating fillers. The increased thermal stability of PA12/HA composite may be attributed to hydrogen bonds existing between the amide group of PA12 and the hydroxyl group of HA, strengthening the interfacial interaction, and requiring more energy to break the bonding. The addition of zirconia also causes an appreciable change in $T_{\mathrm{i}}$, probably due to good dispersion in the polyamide matrix. The small, almost spherical shape of zirconia particles may also improve the packing density, allowing the resin matrix to fill the spaces between the filler particles, resulting in the requirement for a higher temperature to decompose the polyamide matrix. Nevertheless, the maximum temperature $T_{\max }$ of composites decreased, as well as the temperature ranges of $\Delta T$ becoming smaller. Comparing the TGA results on the extrusion and printing process, both results exhibited approximately the same values. This was due to the printing process not influencing the decomposition behaviour associated with the polyamide. The residue identified at the end of a TGA was quantified as inorganic fillers. As shown in Table 4, the filler content or char residue was approximately equal to the experimental filler determined for both pelletised and printed parts. This indicates that the compounding process via a twin-screw extruder provides a homogeneous and adequate dispersion of filler particles in a continuous polymer matrix, consequently leading to a good approximation of filler content in the final printed part.

\section{Conclusions}

In this study, new composite materials consisting of polyamide 12 incorporated with zirconia and hydroxyapatite filled particles were successfully developed using the fused deposition modelling (FDM) $3 \mathrm{D}$ printing technique. The focus was to introduce a new polyamide composite as a potential implant used for biomedical applications. Incorporating small amount of fillers between $10-30 \mathrm{wt} \%$ in the PA12 matrix resulted in either an improvement or a maintenance of the mechanical properties, especially those

Table 4. Thermal properties of PA12 and PA12 composites from TG and DTG curves

\begin{tabular}{|c|c|c|c|c|c|c|}
\hline Sample & $\begin{array}{c}\text { Filler content } \\
{[w t \%]}\end{array}$ & $\begin{array}{l}\text { Actual filler content } \\
{[w \mathrm{wt} \%]}\end{array}$ & $\begin{array}{c}T_{\mathrm{i}} \\
{\left[{ }^{\circ} \mathrm{C}\right]}\end{array}$ & $\begin{array}{c}T_{\mathrm{f}} \\
{\left[{ }^{\circ} \mathrm{C}\right]}\end{array}$ & $\begin{array}{c}\Delta \boldsymbol{T} \\
{\left[{ }^{\circ} \mathbf{C}\right]}\end{array}$ & $\begin{array}{l}T_{\max } \\
{\left[{ }^{\circ} \mathrm{C}\right]}\end{array}$ \\
\hline \multicolumn{7}{|c|}{ Pelletized polyamide } \\
\hline PA12 (100) & 0 & 0.66 & 444.12 & 479.46 & 35.34 & 466.92 \\
\hline $\mathrm{PA} 12 / \mathrm{ZrO}_{2} / \mathrm{HA}(90 / 0 / 10)$ & 10 & 8.54 & 454.38 & 470.51 & 16.13 & 463.14 \\
\hline $\mathrm{PA} 12 / \mathrm{ZrO}_{2} / \mathrm{HA}(85 / 5 / 10)$ & 15 & 14.83 & 454.34 & 472.22 & 17.88 & 464.68 \\
\hline $\mathrm{PA} 12 / \mathrm{ZrO}_{2} / \mathrm{HA}(80 / 10 / 10)$ & 20 & 21.00 & 449.09 & 469.61 & 20.52 & 461.93 \\
\hline $\mathrm{PA} 12 / \mathrm{ZrO}_{2} / \mathrm{HA}(70 / 20 / 10)$ & 30 & 30.63 & 445.88 & 469.57 & 23.69 & 459.51 \\
\hline $\mathrm{PA} 12 / \mathrm{ZrO}_{2} / \mathrm{HA}(60 / 30 / 10)$ & 40 & 40.78 & 447.91 & 474.18 & 26.27 & 466.13 \\
\hline \multicolumn{7}{|c|}{ Printed polyamide } \\
\hline PA12 (100) & 0 & 0.25 & 434.24 & 493.63 & 59.39 & 468.92 \\
\hline $\mathrm{PA} 12 / \mathrm{ZrO}_{2} / \mathrm{HA}(90 / 0 / 10)$ & 10 & 10.56 & 440.92 & 474.71 & 35.48 & 464.93 \\
\hline $\mathrm{PA} 12 / \mathrm{ZrO}_{2} / \mathrm{HA}(85 / 5 / 10)$ & 15 & 14.44 & 441.07 & 471.23 & 30.16 & 463.37 \\
\hline $\mathrm{PA} 12 / \mathrm{ZrO}_{2} / \mathrm{HA}(80 / 10 / 10)$ & 20 & 17.61 & 439.12 & 467.93 & 28.81 & 459.87 \\
\hline $\mathrm{PA} 12 / \mathrm{ZrO}_{2} / \mathrm{HA}(70 / 20 / 10)$ & 30 & 29.34 & 438.79 & 473.36 & 34.57 & 462.31 \\
\hline $\mathrm{PA} 12 / \mathrm{ZrO}_{2} / \mathrm{HA}(60 / 30 / 10)$ & 40 & 38.51 & 443.71 & 475.37 & 31.66 & 463.20 \\
\hline
\end{tabular}


related to the strength and modulus. DSC results revealed that the crystal structure of PA12 is strongly dependent on the thermal history and the applied cooling rate. A low cooling rate during cold crystallisation caused a partial transformation of the $\gamma$-crystal to the $\alpha$-formed crystal. The melting temperature of PA12 was slightly reduced after incorporating the fillers, regardless of different processing techniques. A slight decrease in the degree of crystallinity was observed between the samples prepared through the extrusion and 3D printing process. Meanwhile, a slight effect in the degree of crystallinity was also detected as a result of the type of fillers. From the TGA analysis, incorporating both hydroxyapatite and zirconia, improved the thermal stability of PA12 by increasing the onset of temperature degradation. Overall, the results of the present study, coupled with previous reports on polymer biocomposites, clearly show that the PA composites fabricated by FDM can potentially be used as implant materials, at least for non-loading applications. However, future research work should focus on optimising the processing parameters for PA1 2 composites to further improve the properties of FDM parts and to investigate flow behaviours of PA12 after the incorporation of fillers.

\section{Acknowledgements}

The authors gratefully acknowledge Universiti Sains Malaysia for the financial support of RUT grant 1001/PPSG/852004. First and second authors are supported by MyBrain15 Program under the Ministry of Higher Education, Malaysia.

\section{References}

[1] Ning F., Cong W., Hu Z., Huang K.: Additive manufacturing of thermoplastic matrix composites using fused deposition modeling: A comparison of two reinforcements. Journal of Composite Materials, in press (2017). https://doi.org/10.1177/0021998317692659

[2] Ning F., Cong W., Hu Y., Wang H.: Additive manufacturing of carbon fiber-reinforced plastic composites using fused deposition modeling: Effects of process parameters on tensile properties. Journal of Composite Materials, 51, 451-462 (2016). https://doi.org/10.1177/0021998316646169

[3] Murphy C. A., Collins M. N.: Microcrystalline cellulose reinforced polylactic acid biocomposite filaments for 3D printing. Polymer Composites, in press (2016). https://doi.org/10.1002/pc.24069
[4] Dorigato A., Moretti V., Dul S., Unterberger S. H., Pegoretti A.: Electrically conductive nanocomposites for fused deposition modelling. Synthetic Metals, 226, 714 (2017).

https://doi.org/10.1016/j.synthmet.2017.01.009

[5] Szebényi G., Czigány T., Magyar B., Karger-Kocsis J.: $3 \mathrm{D}$ printing-assisted interphase engineering of polymer composites: Concept and feasibility. Express Polymer Letters, 11, 525-530 (2017). https://doi.org/10.3144/expresspolymlett.2017.50

[6] Wang X., Jiang M., Zhou Z., Gou J., Hui D.: 3D printing of polymer matrix composites: A review and prospective. Composites Part B: Engineering, 110, 442-458 (2017). https://doi.org/10.1016/j.compositesb.2016.11.034

[7] Dul S., Fambri L., Pegoretti A.: Fused deposition modelling with ABS-graphene nanocomposites. Composites Part A: Applied Science and Manufacturing, 85, 181191 (2016).

https://doi.org/10.1016/j.compositesa.2016.03.013

[8] Ning F., Cong W., Qiu J., Wei J., Wang S.: Additive manufacturing of carbon fiber reinforced thermoplastic composites using fused deposition modeling. Composites Part B: Engineering, 80, 369-378 (2015).

https://doi.org/10.1016/j.compositesb.2015.06.013

[9] Weng Z., Wang J., Senthil T., Wu L.: Mechanical and thermal properties of ABS/montmorillonite nanocomposites for fused deposition modeling 3D printing. Materials and Design, 102, 276-283 (2016).

https://doi.org/10.1016/j.matdes.2016.04.045

[10] Hwang S., Reyes E. I., Moon K-S., Rumpf R. C., Kim N. S.: Thermo-mechanical characterization of metal/polymer composite filaments and printing parameter study for fused deposition modeling in the 3D printing process. Journal of Electronic Materials, 44, 771-777 (2014). https://doi.org/10.1007/s11664-014-3425-6

[11] Drummer D., Cifuentes-Cuéllar S., Rietzel D.: Suitability of PLA/TCP for fused deposition modeling. Rapid Prototyping Journal, 18, 500-507 (2012). https://doi.org/10.1108/13552541211272045

[12] Nikzad M., Masood S. H., Sbarski I.: Thermo-mechanical properties of a highly filled polymeric composites for fused deposition modeling. Materials and Design, 32, 3448-3456 (2011). https://doi.org/10.1016/j.matdes.2011.01.056

[13] Seppälä J.: 3D-printed polymers for biomedical applications. Express Polymer Letters, 10, 788 (2016). https://doi.org/10.3144/expresspolymlett.2016.73

[14] Zhang B., Seong B., Nguyen V., Byun D.: 3D printing of high-resolution PLA-based structures by hybrid electrohydrodynamic and fused deposition modeling techniques. Journal of Micromechanics and Microengineering, 26, 025015/1-025015/8 (2016). https://oi.org/10.1088/0960-1317/26/2/025015 
[15] Dávila J. L., Freitas M. S., Inforçatti Neto P., Silveira Z. C., Silva J. V. L., D’Ávila M. A.: Fabrication of PCL/ $\beta$-TCP scaffolds by $3 \mathrm{D}$ mini-screw extrusion printing. Journal of Applied Polymer Science, 133, 43031/143031/9 (2016).

https://doi.org/10.1002/app.43031

[16] Hoque M. E., Meng T. T. H., Chuan Y. L., Chowdhury M., Prasad R. G. S. V.: Fabrication and characterization of hybrid PCL/PEG 3D scaffolds for potential tissue engineering applications. Materials Letters, 131, 255-258 (2014).

https://doi.org/10.1016/j.matlet.2014.05.111

[17] Wang H., Li Y., Zuo Y., Li J., Ma S., Cheng L.: Biocompatibility and osteogenesis of biomimetic nano-hydroxyapatite/polyamide composite scaffolds for bone tissue engineering. Biomaterials, 28, 3338-3348 (2007). https://doi.org/10.1016/j.biomaterials.2007.04.014

[18] Tuan Rahim T. N. A., Abdullah A. M., Akil H., Mohamad D., Rajion Z. A.: Preparation and characterization of a newly developed polyamide composite utilising an affordable 3D printer. Journal of Reinforced Plastics and Composites, 34, 1628-1638 (2015).

https://doi.org/10.1177/0731684415594692

[19] Masood S. H., Song W. Q.: Development of new metal/ polymer materials for rapid tooling using fused deposition modelling. Materials and Design, 25, 587-594 (2004). https://doi.org/10.1016/j.matdes.2004.02.009

[20] Zhou S., Li Y-B., Wang Y-Y., Zuo Y., Gao S-B., Zhang L.: Injection-molded porous hydroxyapatite/polyamide-66 scaffold for bone repair and investigations on the experimental conditions. Polymer Engineering and Science, 54, 1003-1012 (2014).

https://doi.org/10.1002/pen.23636

[21] Castelan-Velazco L. I., Mendez-Nonell J., Sanchez-Valdes S., Ramos-deValle L. F.: Morphology and osteogenetic characteristics of polyamide/nanohydroxyapatite biocomposites. Polymer Bulletin, 62, 99-110 (2009). https://doi.org/10.1007/s00289-008-1014-7

[22] Mehrabanian M., Nasr-Esfahani M.: HA/nylon 6,6 porous scaffolds fabricated by salt-leaching/solvent casting technique: Effect of nano-sized filler content on scaffold properties. International Journal of Nanomedicine, 6, 1651-1659 (2011).

https://doi.org/10.2147/IJN.S21203

[23] Wei J., Li Y., Lau K-T.: Preparation and characterization of a nano apatite/polyamide 6 bioactive composite. Composites Part B: Engineering, 38, 301-305 (2007). https://doi.org/10.1016/j.compositesb.2006.05.006

[24] Nakahira A., Tamai M., Miki S., Pezzotti G.: Fracture behavior and biocompatibility evaluation of nylon-infiltrated porous hydroxyapatite. Journal of Materials Science, 37, 4425-4430 (2002).

https://doi.org/10.1023/A:1020681309572
[25] Hambire U. V., Tripathi V. K.: Optimization of compressive strength of zirconia based dental composites. Bulletin of Materials Science, 37, 1315-1320 (2014). https://doi.org/10.1007/s12034-014-0077-3

[26] Guo G., Fan Y., Zhang J-F., Hagan J. L., Xu X.: Novel dental composites reinforced with zirconia-silica ceramic nanofibers. Dental Materials, 28, 360-368 (2012). https://doi.org/10.1016/j.dental.2011.11.006

[27] Kamali A., Javadpour S., Javid B., Kianvash Rad N., Naddaf Dezfuli S.: Effects of chitosan and zirconia on setting time, mechanical strength, and bioactivity of calcium silicate-based cement. International Journal of Applied Ceramic Technology, 14, 135-144 (2017).

https://doi.org/10.1111/ijac.12636

[28] Yaszemski M. J., Trantolo D. J., Lewandrowski K-U., Hasirci V., Altobelli D. E., Wise D. L.: Biomaterials in orthopedics. Narcel Dekker, New York (2004).

[29] Afzal A.: Implantable zirconia bioceramics for bone repair and replacement: A chronological review. Materials Express, 4, 1-12 (2014). https://doi.org/10.1166/mex.2014.1148

[30] Jin Y., Wan Y., Zhang B., Liu Z.: Modeling of the chemical finishing process for polylactic acid parts in fused deposition modeling and investigation of its tensile properties. Journal of Materials Processing Technology, 240, 233-239 (2017). https://doi.org/10.1016/j.jmatprotec.2016.10.003

[31] Melenka G. W., Schofield J. S., Dawson M. R., Carey J. P.: Evaluation of dimensional accuracy and material properties of the MakerBot 3D desktop printer. Rapid Prototyping Journal, 21, 618-627 (2015). https://doi.org/10.1108/RPJ-09-2013-0093

[32] Chacón J. M., Caminero M. A., García-plaza E., Núñez P. J.: Additive manufacturing of PLA structures using fused deposition modelling: Effect of process parameters on mechanical properties and their optimal selection. Materials and Design, 124, 143-157 (2017). https://doi.org/10.1016/j.matdes.2017.03.065

[33] Lederle F., Meyer F., Brunotte G-P., Kaldun C., Hübner E. G.: Improved mechanical properties of 3D-printed parts by fused deposition modeling processed under the exclusion of oxygen. Progress in Additive Manufacturing, 1, 3-7 (2016).

https://doi.org/10.1007/s40964-016-0010-y

[34] Carneiro O. S., Silva A. F., Gomes R.: Fused deposition modeling with polypropylene. Materials and Design, 83, 768-776 (2015). https://doi.org/10.1016/j.matdes.2015.06.053

[35] Gogolewski S., Czerniawska K., Gasiorek M.: Effect of annealing on thermal properties and crystalline structure of polyamides. nylon 12 (polylaurolactam). Colloid and Polymer Science, 258, 1130-1136 (1980). https://doi.org/10.1007/BF01382456 
[36] Ramakrishna S., Mayer J., Wintermantel E., Leong K. W.: Biomedical applications of polymer-composite materials: A review. Composites Science and Technology, 61, 1189-1224 (2001). https://doi.org/10.1016/S0266-3538(00)00241-4

[37] Wang M., Joseph R., Bonfield W.: Hydroxyapatite-polyethylene composites for bone substitution: Effects of ceramic particle size and morphology. Biomaterials, 19, 2357-2366 (1998).

https://doi.org/10.1016/S0142-9612(98)00154-9

[38] Zhang X., Li Y-B., Zuo Y., Lv G-Y., Mu Y-H., Li H.: Morphology, hydrogen-bonding and crystallinity of nano-hydroxyapatite/polyamide 66 biocomposites. Composites Part A: Applied Science and Manufacturing, 38, 843-848 (2007)

https://doi.org/10.1016/j.compositesa.2006.08.002

[39] Wei J., Li Y., Chen W., Zuo Y.: A study on nano-composite of hydroxyapatite and polyamide. Journal of Materials Science, 38, 3303-3306 (2003).

https://doi.org/10.1023/A:1025194122977

[40] Li J., Zuo Y., Cheng X., Yang W., Wang H., Li Y.: Preparation and characterization of nano-hydroxyapatite/polyamide 66 composite GBR membrane with asymmetric porous structure. Journal of Materials Science: Materials in Medicine, 20, 1031-1038 (2009).

https://doi.org/10.1007/s10856-008-3664-2

[41] Torrado A. R., Shemelya C. M., English J. D., Lin Y., Wicker R. B., Roberson D. A.: Characterizing the effect of additives to $\mathrm{ABS}$ on the mechanical property anisotropy of specimens fabricated by material extrusion $3 \mathrm{D}$ printing. Additive Manufacturing, 6, 16-29 (2015).

https://doi.org/10.1016/j.addma.2015.02.001

[42] Zhong W., Li F., Zhang Z., Song L., Li Z.: Short fiber reinforced composites for fused deposition modeling. Materials Science and Engineering: A, 301, 125-130 (2001).

https://doi.org/10.1016/S0921-5093(00)01810-4

[43] Wu C. S., Liao H. T.: Interface design of environmentally friendly carbon nanotube-filled polyester composites: Fabrication, characterisation, functionality and application. Express Polymer Letters, 11, 187-198 (2017). https://doi.org/10.3144/expresspolymlett.2017.20

[44] Postiglione G., Natale G., Griffini G., Levi M., Turri S.: Conductive 3D microstructures by direct 3D printing of polymer/carbon nanotube nanocomposites via liquid deposition modeling. Composites Part A: Applied Science and Manufacturing, 76, 110-114 (2015). https://doi.org/10.1016/j.compositesa.2015.05.014
[45] Rocha C. R., Torrado Perez A. R., Roberson D. A., Shemelya C. M., MacDonald E., Wicker R. B.: Novel ABS-based binary and ternary polymer blends for material extrusion 3D printing. Journal of Materials Research, 29, 1859-1866 (2014).

https://doi.org/10.1557/jmr.2014.158

[46] Hu G., Ma Y., Wang B.: Mechanical properties and morphology of nylon 11/tetrapod-shaped zinc oxide whisker composite. Materials Science and Engineering: A, 504, 8-12 (2009). https://doi.org/10.1016/j.msea.2008.12.025

[47] Wu T-M., Wu J-Y.: Structural analysis of polyamide/ clay nanocomposites. Journal of Macromolecular Science Part B, 41, 17-31 (2002). https://doi.org/10.1081/MB-120002343

[48] Liu T. X., Liu Z. H., Ma K. X., Shen L., Zeng K. Y., He C. B.: Morphology, thermal and mechanical behavior of polyamide 6/layered-silicate nanocomposites. Composites Science and Technology, 63, 331-337 (2003). https://doi.org/10.1016/S0266-3538(02)00226-9

[49] Fornes T. D., Paul D. R.: Structure and properties of nanocomposites based on nylon-11 and -12 compared with those based on nylon-6. Macromolecules, 37, 76987709 (2004).

https://doi.org/10.1021/ma048757o

[50] Jeziórska R., Świerz-Motysia B., Szadkowska A., Marciniec B., Maciejewski H., Dutkiewicz M., Leszczyńska I.: Effect of POSS on morphology, thermal and mechanical properties of polyamide 6. Polymery, 56, 809-816 (2011).

[51] Dupin S., Lame O., Barrès C., Charmeau J-Y.: Microstructural origin of physical and mechanical properties of polyamide 12 processed by laser sintering. European Polymer Journal, 48, 1611-1621 (2012). https://doi.org/10.1016/j.eurpolymj.2012.06.007

[52] Zhang X., Li Y., Lv G., Zuo Y., Mu Y.: Thermal and crystallization studies of nano-hydroxyapatite reinforced polyamide 66 biocomposites. Polymer Degradation and Stability, 91, 1202-1207 (2006).

https://doi.org/10.1016/j.polymdegradstab.2005.02.006

[53] Athreya S. R., Kalaitzidou K., Das S.: Mechanical and microstructural properties of Nylon-12/carbon black composites: Selective laser sintering versus melt compounding and injection molding. Composites Science and Technology, 71, 506-510 (2011). https://doi.org/10.1016/j.compscitech.2010.12.028 